Article

\title{
The Effect of Building Facades on Outdoor Microclimate-Reflectance Recovery from Terrestrial Multispectral Images Using a Robust Empirical Line Method
}

\author{
Jonathan Fox ${ }^{1,2, *}$, Paul Osmond ${ }^{1(1)}$ and Alan Peters ${ }^{3}$ \\ 1 Faculty of Built Environment, The University of New South Wales (UNSW), Sydney NSW 2052, Australia; \\ p.osmond@unsw.edu.au \\ 2 CRC for Low Carbon Living Ltd, Tyree Energy Technology Building-UNSW, Sydney NSW 2052, Australia \\ 3 School of Architecture and Built Environment, The University of Adelaide, Adelaide SA 5005, Australia; \\ alan.peters@adelaide.edu.au \\ * Correspondence: jonathan.fox@unsw.edu.au; Tel.: +61-(02)-9385-5247
}

Received: 6 June 2018; Accepted: 21 June 2018; Published: 25 June 2018

check for updates

\begin{abstract}
Climate change and the urban heat island effect pose significant health, energy and economic risks. Urban heat mitigation research promotes the use of reflective surfaces to counteract the negative effects of extreme heat. Surface reflectance is a key parameter for understanding, modeling and modifying the urban surface energy balance to cool cities and improve outdoor thermal comfort. The majority of urban surface studies address the impacts of horizontal surface properties at the material and precinct scales. However, there is a gap in research focusing on individual building facades. This paper analyses the results of a novel application of the empirical line method to calibrate a terrestrial low-cost multispectral sensor to recover spectral reflectance from urban vertical surfaces. The high correlation between measured and predicted mean reflectance values per waveband $\left(0.940\right.$ (Red) $<r_{s}>0.967$ (NIR)) confirmed a near-perfect positive agreement between pairs of samples of ranked scores. The measured and predicted distributions exhibited no statistically significant difference at the $95 \%$ confidence level. Accuracy measures indicate absolute errors within previously reported limits and support the utility of a single-target spectral reflectance recovery method for urban heat mitigation studies focusing on individual building facades.
\end{abstract}

Keywords: urban heat mitigation; albedo; cool facades; spectral reflectance; urban remote sensing; empirical line method; building scale

\section{Introduction}

Anthropogenic alterations to the optical, thermal, moisture and aerodynamic properties of city surfaces generate distinct urban climates, typically characterized by the urban heat island (UHI) effect [1]. The UHI effect refers to hotter air (and surface) temperatures observed in cities compared to non-urban surroundings [2]. UHI spatial and temporal characteristics are influenced by synoptic weather conditions $[3,4]$ but UHI formation is attributed to differences in urban surface structure (3-D geometry), cover (land use and permeability), fabric (optical and thermal properties of materials) and metabolism (human activity) compared to non-urban surroundings [5,6]. Geometric and surface characteristics regulate the partitioning of the surface energy balance (SEB) [2] and at any given location surface temperature — and near-surface air temperature under calm conditions $[7,8]$ —is controlled by the surface's SEB [9]. 
UHIs develop in most cities regardless of climate [10] and have been observed globally in over 400 urban areas [4]. The magnitude of the screen height air temperature difference between urban and non-urban locations, or between different Local Climate Zones [10], is quantified by the "UHI intensity" which is most pronounced during calm, clear summer nights [2]. The average maximum UHI intensity for 87 European cities has been reported to be almost $6.2 \mathrm{~K}$ within a range of $2.8 \mathrm{~K}$ to $12 \mathrm{~K}$ [11]. Similar magnitude UHI intensities were reported for 101 Asian and Australian cities [12].

The superimposition of inadvertent urban heating (i.e., UHIs) and global warming, including more frequent, longer and intense heat waves [13-15] elevates the risk of heat-related mortality and illness in cities [16-18] and extreme urban heat has detrimental outdoor comfort, economic and building energy impacts [19-21]. The intentional modification of urban surface geometry, cover and fabric to reduce urban heat and decouple heat waves from amplified UHIs [22,23] is now a policy priority for many cities [24,25].

\subsection{Urban Heat Mitigation-Current Status and Cooling Magnitude}

In summer, solar absorption by urban surfaces is the dominant cause of the UHI effect [5]. Recent efforts to mitigate the formation of urban heat at different spatial scales have focused on changes to urban surface geometry and fabric [26-28] with the primary aim of controlling the absorption of solar radiation and increasing moisture availability [22,29]. However, due to the significant urban surface and air temperature reduction potential of reflective technologies $[19,30]$ heat mitigation solely focusing on "cool" materials—-those with high solar reflectance and high infrared emittance [31-33] —applied to building envelopes (roofs and walls) and urban structures (roads, squares and footpaths) dominates current scientific research and the global implementation of UHI mitigation technologies [34].

An analysis of 75 simulation studies using reflective materials on roofs and pavements reported average peak and absolute maximum screen-height air temperature reductions of $1.43 \mathrm{~K}$ and $3.4 \mathrm{~K}$ respectively for their combinations [35]. The same study reported average reductions in air temperature of $0.23 \mathrm{~K}$ and $0.27 \mathrm{~K}$ per $10 \%$ increase in albedo for cool roofs and cool pavement technologies respectively. However, despite widespread acceptance of the cooling benefits of reflective technologies and the implementation of numerous large-scale projects using reflective roof and pavement materials [36], more rigorous experimental monitoring, consistent metadata reporting and detailed information on their reduced performance over time and potential outdoor comfort impacts are still required [37-39].

\subsection{Urban Heat Mitigation-Principles of Reflective Technology}

The primary summer daytime energy input into the urban canopy layer (UCL) is solar radiation, which is reflected or absorbed by solar-exposed terrestrial surfaces [1]. Depending on surface characteristics, solar radiation is partitioned into radiative, sensible, latent or storage heat fluxes $[2,40,41]$. Radiative and sensible heat fluxes dominate the SEB in the absence of moisture [42,43]. Sensible heat—or the perceptible rise in air temperature-is amplified when the difference between surface and ambient temperatures is large $[44,45]$. A reduction in the surface's surface temperature, which is achieved by shade or increasing the surface's reflectance [46,47] constrains the convective transfer intensity to the surrounding air [44], thus limiting the transfer of heat to the adjacent air volume $[42,43,48]$ although the relationship between surface and near-surface air temperature is complex [49].

Conversely, surfaces with lower solar reflectance absorb more solar energy, thereby heating the surface, and through strengthened convective transfer [45], warm the adjacent air volume [46,50]. Additionally, via long-wave radiative transfer, hotter surfaces emit infrared radiation to cooler objects within view [51]. In summary, increasing surface reflectance-which in the solar spectrum is referred to as the surface's albedo-potentially reduces the surface's surface temperature, the convective transfer intensity to the air and the emitted infrared radiation to surfaces in view.

However, higher solar reflectance within cities may also increase reflected solar radiation to near-surface facets and people [37,51-59] although the magnitude of reflected solar radiation and its 
impact on human outdoor thermal comfort is highly context-dependent $[37,53,60]$ and few studies have been experimentally determined [52,54].

\subsection{Methods for Measuring Solar Reflectance-Nomenclature}

The albedo of a surface is defined as its hemispherical and wavelength-integrated reflectance [50] and broadband albedo is the ratio of reflected to incident (direct and diffuse) solar radiation (250-3000 nm), or the fraction of incident sunlight reflected by the surface quantified from 0 to 1 [61]. The albedo of a terrestrial surface may vary with the wavelength $(\lambda)$ of incident radiation (spectral dependence), the angle of incidence $(\theta)$ of radiation (angular dependence of direct and diffuse components) and the surface's surface structure and roughness [61,62].

In remote sensing and field measurements reflectance quantities are acquired under sky conditions and surface albedo is influenced by atmospheric turbidity, solar position, surface orientation and the geometry and optical properties of the surrounding urban form [62,63]. Solar irradiance consists of both direct beam and diffuse components and therefore the solar reflectance of a surface is variable in time and place (as atmospheric conditions and solar position change) and constant albedo values assume spectral and angular independence [62].

The use of laboratory, field or remote sensing methods for the measurement of surface reflectance is determined by the experimental design, material characteristics (e.g., sample size, etc.), spatial scale and wavelength and directional parameters of interest [64-66]. Reflectance nomenclature describes measured reflectance values first by the incident, and secondly by the reflected, angular distribution of radiation [63]. Levinson et al. [66] provide a comprehensive review of standard reflectance measurement methods and only remotely-sensed reflectance methods are briefly discussed further here.

\subsection{Methods for Measuring Solar Reflectance-Remote Sensing of Urban Surfaces Using Narrow Field of View (FOV) Sensors}

The standards-based laboratory [67] and field methods [68,69] for albedo measurement provide single reflectance quantities of small $\left(0.1-5 \mathrm{~cm}^{2}\right)$, flat, homogenous surfaces or the hemispherically-integrated value of larger $\left(>1 \mathrm{~m}^{2}\right)$ horizontal and low-sloped homogeneous diffusely-reflecting surfaces or the aggregate quantity of non-uniform horizontal surfaces [70] with relatively high accuracy (error $<2 \%$ ) [66]. However, the aforementioned methods have several limitations when applied to real urban surfaces $[64,66,71,72]$.

Since the microclimate impacts of urban vertical surfaces are spatially dependent $[54,73-76]$ and may be significantly influenced by microstructure heterogeneity [77] the ability to compute the spatial and geometric distribution of reflectance at sub-facet scale $(<10 \mathrm{~m})$ is desirable [78-82]. Satellite, aerial and ground-based remote sensing technologies permit increasing spatial, spectral, radiometric and temporal resolution with greater spatial coverage $[48,83,84]$. Ground-based imaging sensors are lightweight and mobile enabling in-canyon observations of surfaces with relative operational simplicity [85].

Remote sensors record wavelength-dependent energy emanating from a surface within the sensor's FOV. At short path lengths near the ground $(<100-200 \mathrm{~m})$ atmospheric absorption may be considered to be negligible $[84,86,87]$. Image data from image sensors are composed of discrete picture elements (pixels) each with a potentially unique brightness (or digital number, DN) value and ground resolution or instantaneous field of view (IFOV) determined by the sensor optics [84]. Depending on target distance, a ground-based image of a building wall or horizontal urban surface is "automatically" resolved into sub-facet (IFOV) scale surface brightness values that, once calibrated to spectral radiance [63] and geolocated, can be used to derive spatially-registered per-pixel spectral reflectance quantities based on the experimentally determined correlation between surface reflectance and at-sensor radiance $[48,88,89]$.

Obtaining reflectance data in both the visible and NIR wavelengths improves surface albedo estimates, since many urban materials strongly reflect in the NIR region $[31,48,90]$. Multispectral (MS) 
sensors are spectrally selective and simultaneously record reflected radiation in several discrete narrow bandwidths, for example in Green (520-600 nm), Red (630-690 nm) and NIR (760-920 nm) [91,92]. Reflectance quantities derived from ground-based sensors with narrow FOV (and with knowledge of the surfaces' spectral and angular dependence [48]) are "hemispherical-canonical" reflectance values (per [63]) where direct and diffuse sky radiation is reflected into a narrow sensor viewing geometry [63]. A maximum absolute error of $14 \%$ has been reported for remotely measured albedo values of horizontal and low-sloped urban roofs from radiometrically calibrated high-resolution (1 m) aerial imagery with a smaller error $(<2 \%)$ for low albedo $(<0.2)$ surfaces [48].

\subsection{Methods for Measuring Solar Reflectance-Overview of the Emprical Line (EL) Method}

Remotely sensed image data of reflected energy received by a passive sensor is typically represented by a matrix of pixels containing DNs that are in value proportional to the intensity of energy reflected by the surface within view [92]. However, the proportionality relationship between image DNs and physical units such as surface reflectance is influenced by camera characteristics (i.e., the spectral response curve and analogue-to-digital signal conversion of the sensor [92]), sun-surface-sensor geometry (i.e., anisotropy of reflected radiation and illumination conditions [93]) and, for larger path distances, atmospheric transmittance [48]. Hence, DNs alone contain little meaningful quantitative information about surface reflectance unless the sensor is radiometrically calibrated [88].

Empirical (or "vicarious") radiometric calibration using in-situ reference targets of known spectral reflectance correlated to at-sensor radiance for each sensor waveband robustly accounts for atmospheric and illumination effects and produces acceptable radiance-to-reflectance conversion results [48,88]. Despite its widespread use the method is error prone if implemented without logistical and methodological considerations [88,94]. For many inexpensive, commercially available MS cameras the relationship between at-sensor spectral radiance and image DNs is not readily available [95,96], is onerous to obtain [48,97] and may be non-linear [98] and the unique camera response function-the gain and offset coefficients used to convert the radiance-as-electrical signal to output digital numbers [92]—requires determination before DNs can be converted to reflectance units $[99,100]$. In this case, the reflectance-based calibration method can be used to predict at-sensor radiance (expressed as image DNs) by measuring the reflectance of a calibration target $[94,100]$.

Typically, an ordinary least squares (OLS) regression equation of spectral reflectance (y-axis) against DNs (x-axis) is computed for each sensor waveband from the mean spectral reflectance values of at least two spectrally distinct ground calibration targets and the mean DNs from the corresponding region of interest (ROI) in the image [88]. The EL equation is then validated in the field using spectral reflectance values measured by a field spectrometer or supplementary targets of known reflectance [86,99]. Mean DNs retrieved from remotely sensed MS images are then used as input data to the per-waveband predictive equations to generate per-pixel spectral reflectance values $[86,96,101,102]$. Several authors have developed simplified protocols using vicarious calibration methods to reduce the number of high-cost, in-situ and in-image targets [86,98].

While studies using EL methods for reflectance recovery are increasingly common to derive vegetation characteristics in open fields ([86] and references therein) the use of the EL method for reflectance recovery from urban surfaces is less common due to logistical and methodological challenges posed by urban areas [5] but interest in applications to man-made and urban surfaces is growing [94,103,104].

\subsection{Purpose and Significance of the Work}

Surface properties and impacts of cool roof and paving technologies have been extensively studied and applied [19,26,32,36,46,105-107]. However, research into the microclimate impacts of urban vertical surfaces and the effect of building facade geometry and fabric remain relatively underdeveloped [44]. While research into the optical properties, thermal and energy performance and outdoor thermal comfort impacts of cool materials for use in building envelopes is more advanced [36,37,54,72,73,108-113], the conceptualisation 
of building facades as more than merely an ensemble of material "facets" (or discrete, homogenous, surfaces [5]) and the development of climate sensitive architectural design applications that progress beyond a singular focus on cool and smart material specification [114-116] are still emerging (e.g., [117-120]).

While microclimate modelling and simulation tools exist and are fundamentally useful [121-123] comparatively few have been validated in the field [124] and none explicitly provide architects with meaningful "thermo-semantics"- the synthesis of building envelope thermal and optical performance computation and architectural design-at scales and interests commensurate with architects' decision-making [125].

This paper is part of ongoing research into the development of a thermo-semantic tool intended to assist architects to evaluate the outdoor thermal impacts of building facade design based on a vertical surface thermal typology supported by a predictive statistical model. The reflectance recovery method described here was applied to multispectral image panoramas of sampled building facades to create reflectance datasets for input to a probabilistic model.

The development of low-cost, replicable methods for reflectance recovery from real urban vertical surfaces within the UCL addresses the need for improved observation, understanding and transdisciplinary communication of urban atmospheric process at multiple scales and particularly at the street-level human scale [126] and contributes to the development of a predictive science of microclimatology [125]. Close-range ground-based reflectance recovery complements but also has some advantages over emerging unmanned aerial vehicle (UAV) technologies, particularly in relation to the statutory height and air-space restrictions applicable to UAVs in dense urban areas [86,127].

\section{Materials and Methods}

\subsection{Overview of Method}

To recover per-pixel spectral reflectance from MS digital images the relationship between known reflectance values per camera waveband and image DN distributions was statistically modelled as EL equations [88]. Two sets of alternative camera calibration targets were used to derive the theoretical constant "camera response function" and a second calibration target of higher reflectance was used to derive the variable "slope coefficient" [98]. The reflectance recovery method was evaluated by comparing known reflectance values of common building materials used in building facades with those derived from the final empirical line equations applied in ArcMap (ArcGIS by ESRI) to colour-processed MS images of the same materials. Predictive model precision and accuracy measures $[128,129]$ were used to determine the optimum equations for later application to recover per-pixel spectral reflectance from MS panoramas of sixty mid-rise building facades (not discussed further here).

\subsection{Camera Description}

Tetracam Inc.'s Agricultural Digital Camera (ADC) (Tables 1 and 2) was used to capture images of the calibration targets. Images were stored using an uncompressed 10-bit per-pixel RAW (RAW) file format in automatic exposure mode (set to average).

Table 1. Tetracam ADC multispectral camera specifications ${ }^{1}$.

\begin{tabular}{cc}
\hline Description & Specification \\
\hline Image resolution & $2048 \times 1536$ pixels $(3.2$ Megapixels) \\
Spectral range & $0.52-0.92 \mu \mathrm{m}$ \\
Lens focal length $(f)$ & $8 \mathrm{~mm}$ \\
Instantaneous field of view (IFOV) & $0.3975 \mathrm{mrad}$ \\
Image storage format & RAW $10(10 \mathrm{bits})$ \\
Processed image format & 8 bit JPEG $(256$ units $)$ \\
Horizontal field of view (HFOV) & $44.75^{\circ}$ \\
\hline
\end{tabular}

${ }^{1}$ Source: Tetracam data sheet for ADC camera S/N 221215. 
Table 2. Tetracam ADC camera waveband, bandwidth and colour channel specifications ${ }^{1}$.

\begin{tabular}{cccc}
\hline Waveband & ADC Bandwith (Range) & Colour Channel & Landsat TM \\
\hline Green & $520-600 \mathrm{~nm}(80 \mathrm{~nm})$ & $\mathrm{B}$ & TM2 \\
Red & $630-690 \mathrm{~nm}(60 \mathrm{~nm})$ & $\mathrm{G}$ & TM3 \\
NIR & $760-920 \mathrm{~nm}(160 \mathrm{~nm})$ & $\mathrm{R}$ & TM4 \\
\hline \multicolumn{4}{c}{ ' Source: Tetracam data sheet for ADC camera S/N 221215. }
\end{tabular}

\subsection{Camera Calibration Target Sets and Spectrophotometer Measurements}

Two sets of camera calibration targets were used to develop the optimal EL model of the camera response function that describes the theoretical minimum reflectance per waveband detectable by the sensor [98]. Set 1 consisted of twelve A4-size stiff cardboard cards factory-painted with selected Dulux acrylic colours. The cards had a wide range (approx. 13\% to 100\%) of mean near-normal beam hemispherical spectral reflectance values (Refer Table 3, Figure 1) measured using a Perkins Elmer Lambda 950 UV/VIS/NIR spectrophotometer over a 250-1000 nm range at $5 \mathrm{~nm}$ intervals with a $150 \mathrm{~mm}$ integrating sphere calibrated with a $99 \%$ Spectralon certified reflectance standard in compliance with [67].

Table 3. Dulux colour card IDs and measured mean spectral reflectance values ${ }^{1}$.

\begin{tabular}{cccccc}
\hline ID & Colour Name & Dulux Code & $\mathbf{\% R}^{-G_{\boldsymbol{\lambda}}}$ & $\mathbf{\% R}^{-\mathbf{R}_{\boldsymbol{\lambda}}}$ & $\mathbf{\% R}^{-\mathbf{N I R}_{\boldsymbol{\lambda}}}$ \\
\hline 1 & Black & PN2A9 & 13.852 & 14.147 & 15.338 \\
2 & Mt Eden & PN2A7 & 18.984 & 19.140 & 19.150 \\
3 & Klute & PN2A5 & 30.356 & 29.294 & 28.015 \\
4 & Stepney & PN2A3 & 37.794 & 37.083 & 35.243 \\
5 & Warm Granite & PN2C6 & 46.216 & 47.241 & 45.783 \\
6 & Soft Beige & PN2C5 & 56.919 & 57.773 & 57.367 \\
7 & Bleaches & PN2D5 & 65.578 & 65.421 & 65.816 \\
8 & Terrace White & PN2H2 & 78.332 & 76.312 & 78.940 \\
9 & Manorburn & PN2H1 & 80.151 & 79.341 & 80.364 \\
10 & Snowy Mountains & PN2B2 & 87.562 & 87.693 & 89.320 \\
11 & Lexicon Quarter & SW1E1 & 99.232 & 98.952 & 100.00 \\
\hline
\end{tabular}

${ }^{1}$ Mean spectral reflectance values over ADC camera bandwidths.

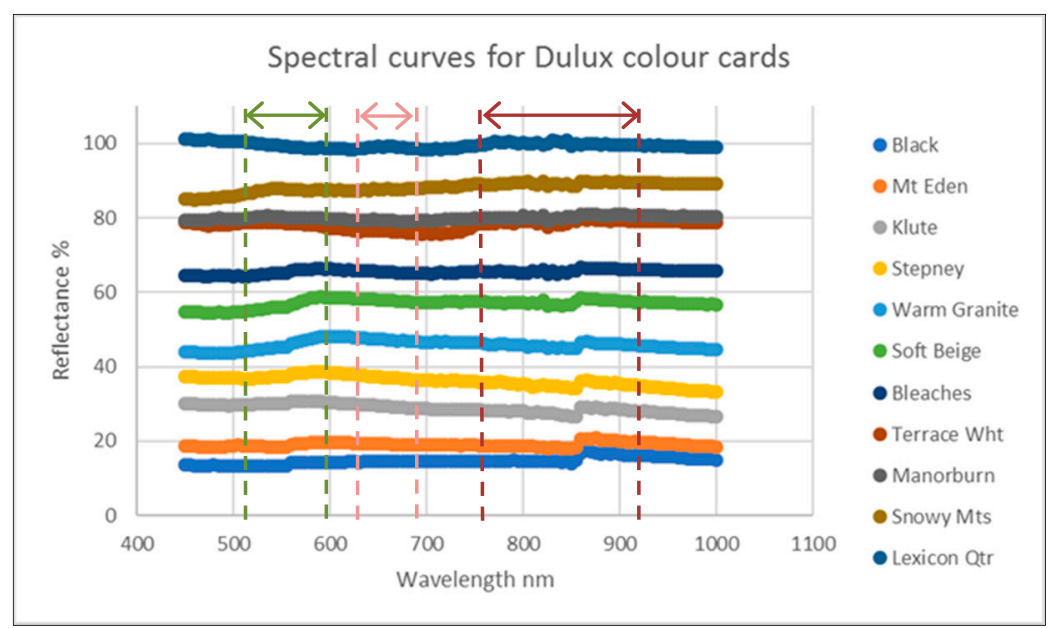

Figure 1. Dulux colour cards reflectance curves $450-1000 \mathrm{~nm}$ at $5 \mathrm{~nm}$ intervals.

The Dulux cards were selected for conformity to the recommended calibration target qualities of uniform, matte surface (assumed here to be diffusely reflecting or Lambertian), near-uniform 
reflectance over the bandwidths of interest and with high spectral contrast [88]. Measuring spectral reflectance at $5 \mathrm{~nm}$ intervals adequately records the spectral characteristics of most surfaces [66].

Camera calibration target Set 2 consisted of one $127 \times 127 \mathrm{~mm}$ Spectralon multi-step diffuse calibration target (Labsphere Inc., North Sutton, NH, USA) with four side-by-side vertical panels of $12 \%, 25 \%, 50 \%$ and $99 \%$ nominal spectral reflectance values measured at $1 \mathrm{~nm}$ intervals from 250 to $2500 \mathrm{~nm}$ using a Perkins Elmer Lambda 900B UV/VIS/NIR dual beam spectrophotometer with $150 \mathrm{~mm}$ integrating sphere that collects 8-degree beam hemispherical reflectance (spectral and diffuse) calibrated with a Spectralon reflectance standard [130] (Refer Table 4, Figure 2).

Table 4. Spectralon multi-step target ID and mean spectral reflectance values ${ }^{1}$.

\begin{tabular}{|c|c|c|c|c|}
\hline ID & Panel Name & $\% R-G_{\lambda}$ & $\% R_{-} \mathbf{R}_{\lambda}$ & $\%$ R-NIR ${ }_{\lambda}$ \\
\hline 1 & SRT-12 & 11.860 & 12.305 & 13.198 \\
\hline 2 & SRT-25 & 27.029 & 28.303 & 30.545 \\
\hline 3 & SRT-50 & 50.320 & 51.820 & 54.204 \\
\hline 4 & SRT-99 & 99.073 & 99.006 & 98.942 \\
\hline
\end{tabular}

${ }^{1}$ Mean spectral reflectance values over ADC camera bandwidths.

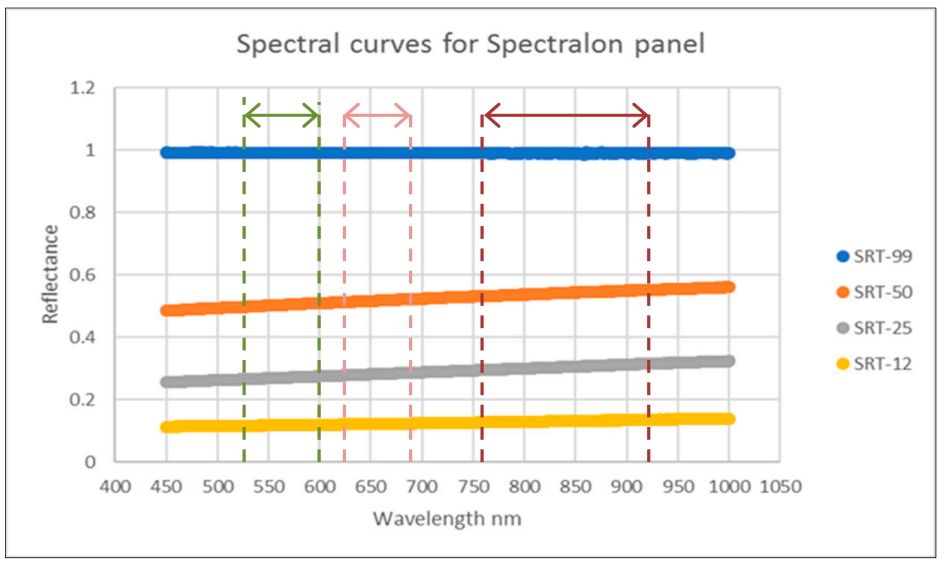

Figure 2. Spectralon multi-step reflectance curves $450-1000 \mathrm{~nm}$ at $1 \mathrm{~nm}$ intervals.

\subsection{Camera Calibration Image Acquisition}

The Dulux cards and the Spectralon multi-step target were placed vertically on a horizontal ledge adjacent a sun-exposed building wall (Figure 3).

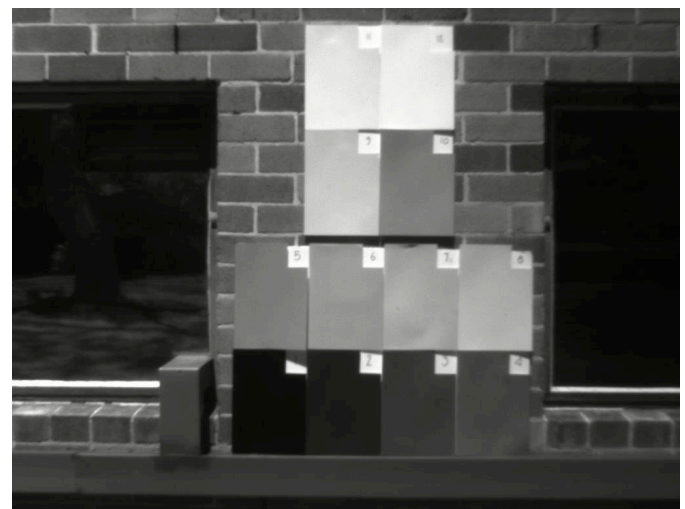

(a)

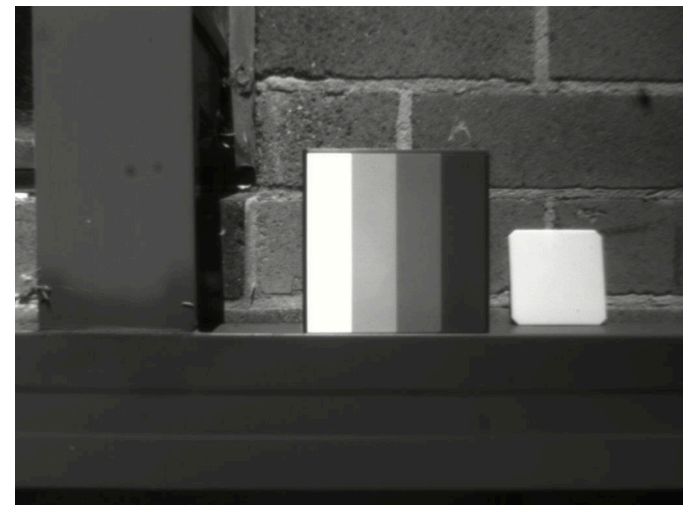

(b)

Figure 3. Dulux colour cards (a) and Spectralon multi-step calibration target (striped) (b). 
Images were taken of the calibration targets outdoors under clear-sky conditions on 15 October 2016 between 12:00 and 12:15 p.m. The solar altitude and azimuth at 12:05 p.m. were $63^{\circ} 23^{\prime} 06^{\prime \prime}$ and $20^{\circ} 09^{\prime} 15^{\prime \prime}$ respectively at $33^{\circ} 55^{\prime} 00^{\prime \prime}$ south latitude and $151^{\circ} 13^{\prime} 00^{\prime \prime}$ east longitude [131]. Multiple images were taken normal to the Dulux and Spectralon targets at distances of $3.2 \mathrm{~m}$ and $1 \mathrm{~m}$ respectively. The target sizes satisfied the recommendations in the literature to be a minimum 3 to 10 times the sensor IFOV [87-98,132] to ensure that as many pixels as possible associated with each calibration target were selected [88] and to avoid atmospheric effects [87]. Each Dulux panel and the Spectralon target measured $293(\mathrm{~h}) \times 210 \mathrm{~mm}(\mathrm{w})$ and $127 \times 127 \mathrm{~mm}$ respectively (with a single multi-step column measuring $30 \mathrm{~mm}(\mathrm{w}) \times 120 \mathrm{~mm}(\mathrm{~h})$ ). Table 5 lists the camera calibration target distances, IFOV and minimum recommended target sizes.

Table 5. Camera calibration target distances and IFOV to satisfy target size requirements.

\begin{tabular}{cccccc}
\hline Target & Target Size & Distance & Sensor IFOV $^{\mathbf{1}}$ & Min. $\mathbf{3} \times$ IFOV & Min. $\mathbf{1 0} \times$ IFOV \\
\hline Spectralon & $30 \mathrm{~mm}$ & $1 \mathrm{~m}$ & $0.4 \mathrm{~mm}$ & $1.2 \mathrm{~mm}$ & $4 \mathrm{~mm}(<30 \mathrm{~mm})$ \\
Dulux & $210 \mathrm{~mm}$ & $3.2 \mathrm{~m}$ & $1.27 \mathrm{~mm}$ & $3.81 \mathrm{~mm}$ & $12.7 \mathrm{~mm}(<210 \mathrm{~mm})$ \\
\hline \multicolumn{5}{c}{ IFOV calculated from FOV optical calculator in Tetracam PW2 software. }
\end{tabular}

\subsection{Multispectral Image Pre-Processing}

The ADC image data were stored in RAW format on a single SanDisk compact flash card and downloaded via a card reader for processing on a PC. The ADC is supplied with a camera-specific colour process file $(\mathrm{CPF})$ that evaluates each RAW pixel value using a colour processing algorithm to extract NIR (760-920 nm), Red (630-690 nm) and Green (520-600 nm) waveband values for each pixel [133]. Colour-processed images were analysed in 10-bit RAW format and later saved in 8-bit JPEG format for import into ArcMap.

To minimize the effects of saturation on the colour processed images the "Auto Adjust Scaling" (AAS) box was checked on the Matrix page of the proprietary image editing software PixelWrenchII (PW2) [133]. As previously reported, saturation of the Tetracam ADC images may occur for high reflectance surfaces when the DNs exceed 256 resulting in the actual reflectance values exceeding the dynamic range of the sensor $[98,134]$.

\subsection{Derivation of Camera Calibration Equations}

The mean DN per waveband was calculated from a uniform polygon region of interest (ROI) within the borders of the colour-processed image of each calibration target using the Histogram Tool in PW2. For each calibration sample the spectrophotometer-measured mean spectral reflectance per-waveband (on the y-axis) was regressed against the corresponding mean DN (on the x-axis) to derive the per-waveband "camera response function" or empirical line 1 (EL1) using the curve estimation function in the statistical software IBM SPSS. The OLS regression equations and scatter plots are shown in Tables 6 and 7 and Figures 4 and 5 below.

Table 6. OLS equations (EL1) of camera response function per waveband for Dulux samples.

\begin{tabular}{cccc}
\hline Wavelength (ADC Channel) & Dulux-Generated EL1 & R & $\mathbf{R}^{\mathbf{2}} ;$ AdjR $^{\mathbf{2}}$ \\
\hline Green $\lambda$ 520-600 nm (Blue) & $\% \mathrm{RG}_{\lambda}=7.7353+0.3607 \mathrm{DN}_{\mathrm{aveB}}$ & 0.989 & $0.978 ; 0.976$ \\
Red $\lambda$ 630-690 nm (Green) & $\% \mathrm{RR}_{\lambda}=5.7211+0.4878 \mathrm{DN}_{\mathrm{aveG}}$ & 0.986 & $0.971 ; 0.968$ \\
NIR $\lambda$ 760-920 nm (Red) & $\% \mathrm{R}_{\mathrm{NIR} \lambda}=7.1711+0.5143 \mathrm{DN}_{\mathrm{aveR}}$ & 0.988 & $0.977 ; 0.974$ \\
\hline
\end{tabular}

Table 7. OLS equations (EL1) of camera response function per waveband for Spectralon samples.

\begin{tabular}{cccc}
\hline Wavelength (ADC Channel) & Dulux-Generated EL1 & $\mathbf{R}$ & $\mathbf{R}^{\mathbf{2}} ;$ Adj $^{\mathbf{2}}$ \\
\hline Green $\lambda$ 520-600 nm (Blue) & $\% \mathrm{R}_{\mathrm{G} \lambda}=6.7622 \exp ^{(0.0132 . D N a v e B)}$ & 0.982 & $0.964 ; 0.947$ \\
Red $\lambda$ 630-690 nm (Green) & $\% \mathrm{R}_{\mathrm{R} \lambda}=0.4761 \mathrm{DN}_{\text {aveG }}-8.4403$ & 0.999 & $0.998 ; 0.997$ \\
NIR $\lambda$ 760-920 nm (Red) & $\% \mathrm{R}_{\mathrm{NIR} \lambda}=0.4803 \mathrm{DN}_{\mathrm{aveR}}-5.1695$ & 0.999 & $0.998 ; 0.998$ \\
\hline
\end{tabular}




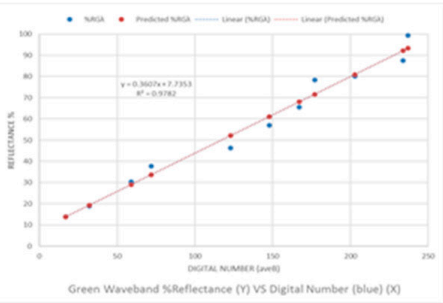

(a)

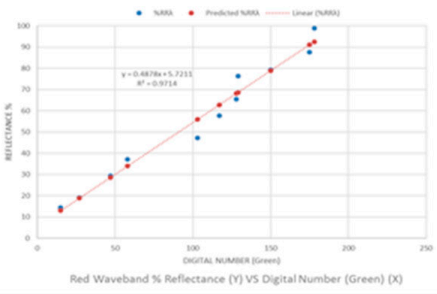

(b)

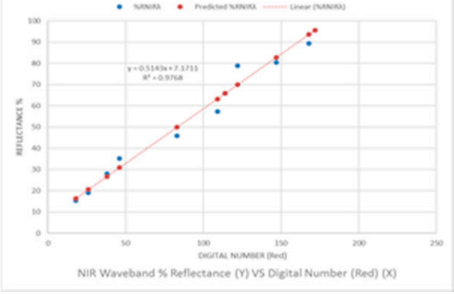

(c)

Figure 4. Plots of: Green (a); Red (b); and NIR (c) camera response functions for the Dulux targets.

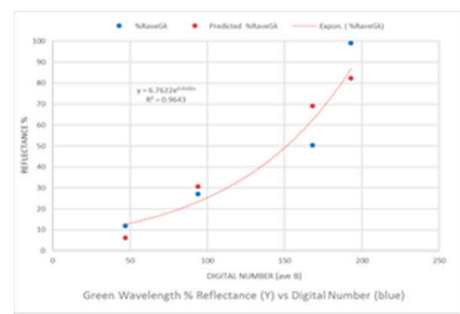

(a)

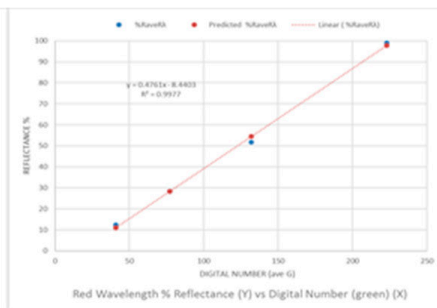

(b)

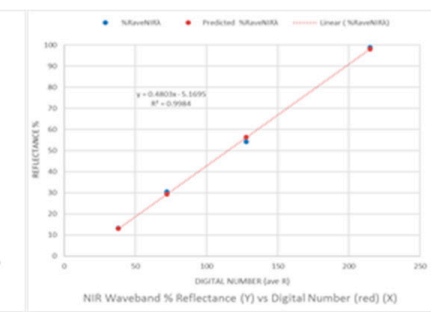

(c)

Figure 5. Plots of: Green (a); Red (b); and NIR (c) camera response functions for the Spectralon targets.

The plots of spectral reflectance against sensor DN for the Dulux targets depict a strong positive linear relationship for all three wavebands as measured by Pearson's correlation coefficient $\left(0.986_{\text {red }}<R_{\text {Dulux }}>0.989_{\text {green }}\right)$. For all sensor wavebands the coefficient of determination exceeds 0.971. The plots of spectral reflectance against sensor DN for the Spectralon calibration target depict a strong linear correlation for Red and NIR wavebands $(R=0.999)$ and an exponential relationship for the Green waveband. $R^{2}$ for Red and NIR were both 0.998 and lowest at 0.964 for Green.

\section{Assessment of Camera Calibration Equations}

When the $x$-intercept $(\mathrm{DN})$ equals 0 the corresponding $y$-intercept values are theoretically the minimum reflectance values detectable by the unique image sensor per waveband [98]. Comparative results of the Dulux and Spectralon-derived camera response equations (Tables 6 and 7) indicate that in this instance, the y-intercept is not a true "constant calibration parameter" [98], since under identical illumination conditions the minimum possible detectable mean spectral reflectance varies depending on the properties of the calibration target [92,135].

In consideration that the spectral curves of both calibration target sets (Figures 1 and 2) indicate near-uniform reflectance over the bandwidths of interest and the Spectralon target is a diffuse reflector, the difference between the camera response to the calibration target sets may be accounted for, in part, by the non-Lambertian reflectance and material properties of the Dulux cards $[86,88,136]$ although this reflectance anisotropy has not been experimentally verified.

\subsection{Derivation of "Slope Coefficient" from In-Situ Calibration Target-Theory and Method}

When two or more calibration targets with large spectral contrast are used the EL method permits the computation of the sensor-specific relationship between image DNs and surface spectral reflectance [88]. In many instances, however, it is impractical or expensive to acquire every image containing its own calibration targets [86]. Wang and Myint [98] developed a simplified method to convert image DNs to spectral reflectance by constructing an EL equation per image waveband that consists of the theoretically minimum possible detectable reflectance or "constant calibration parameter" and one additional coordinate—the "slope coefficient"—-derived from a single field calibration target of higher reflectance. The slope coefficient accounts for the variable illumination effects on sensor DNs when the camera settings are invariant [98]. 
The MS images of the target building facades included a mobile meteorological station crowned by an aluminium "calibration bracket" $(\mathrm{CB})$ measuring $97(\mathrm{w}) \times 95 \mathrm{~mm}(\mathrm{~h})$ with a white powder-coated low-sheen finish. The CB dimensions satisfied the target distance recommendations in the literature for this validation study and final reflectance recovery from images of building facades (Table 8).

Table 8. Facade target distance and IFOV to satisfy minimum target size requirement.

\begin{tabular}{cccccc}
\hline Target & Target Size & Distance & Sensor IFOV & Min. $\mathbf{3} \times$ IFOV & Min. $\mathbf{1 0} \times$ IFOV \\
\hline $\mathrm{CB}$ & $95 \mathrm{~mm}$ & $18.5 \mathrm{~m}(\mathrm{mean})$ & $7.40 \mathrm{~mm}$ & $22.20 \mathrm{~mm}$ & $74 \mathrm{~mm}(<95 \mathrm{~mm})$ \\
\hline \multicolumn{5}{c}{ IFOV calculated from FOV optical calculator in Tetracam PW2 software. }
\end{tabular}

The mean near-normal beam hemispherical spectral reflectance values per waveband of the CB were measured using a Perkins Elmer Lambda 1050 UV/VIS/NIR spectrophotometer over a 250-2500 $\mathrm{nm}$ range at $1 \mathrm{~nm}$ intervals with a $150 \mathrm{~mm}$ integrating sphere calibrated with a 99\% Spectralon certified reflectance standard compliant with [67] (Table 9 and Figure 6).

Table 9. Calibration bracket (CB) mean spectral reflectance values ${ }^{1}$ per camera waveband.

\begin{tabular}{ccccc}
\hline Item & Coordinate & $\% \mathbf{R}-G_{\boldsymbol{\lambda}}$ & $\% \mathbf{R}-\mathbf{R}_{\boldsymbol{\lambda}}$ & $\% \mathbf{R}-\mathrm{NIR}_{\boldsymbol{\lambda}}$ \\
\hline$\% \mathrm{R}_{\mathrm{CB}}$ & "By" & 89.061 & 86.868 & 84.113 \\
\hline
\end{tabular}

${ }_{1}^{1} \overline{\text { Mean spectral reflectance values over ADC camera bandwidths. }}$.

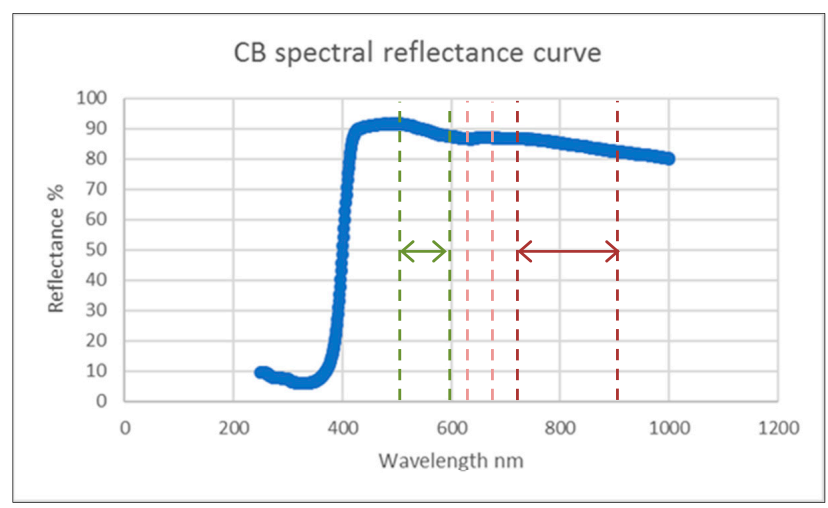

Figure 6. Calibration bracket reflectance curve $250-1000 \mathrm{~nm}$ at $1 \mathrm{~nm}$ intervals.

The following equations derived from [98] constitute the final EL equations per waveband:

$$
\begin{gathered}
\% \mathrm{R}_{\lambda}=m \times \mathrm{DN}_{\text {ave }(\lambda)}+A y \\
m=\text { slope }=\Delta \mathrm{Y} / \Delta \mathrm{X}=(B y-A y) / B x
\end{gathered}
$$

where $A y$ is the $y$-intercept of EL1, when $A x=0 . B y$ is the measured mean spectral reflectance of the calibration bracket and $B x$ is the mean DN corresponding to $B y$.

Multispectral images of the $\mathrm{CB}$ were acquired at the same time as those of the material validation samples. The mean DN per waveband for the CB (Table 10) was calculated from a uniform polygon ROI within the borders of the colour-processed image of the CB using the Histogram Tool in PW2 software.

Table 10. Calibration bracket mean digital number $(\mathrm{DN})$ values ${ }^{1}$ per camera waveband.

\begin{tabular}{ccccc}
\hline Item & Coordinate & $\mathbf{D N}_{\mathrm{G} \lambda}$ & $\mathbf{D N}_{\mathbf{R} \lambda}$ & $\mathbf{D N}_{\mathrm{NIR} \lambda}$ \\
\hline $\mathrm{DN}$ & "Bx" & 254 & 211 & 199 \\
\hline
\end{tabular}

1 Mean DNs were calculated from the average of five ROIs. 
The final EL equations per waveband ("EL2") derived from the intercept obtained from EL1 equations and the slope coefficient derived from the slope values calculated from Equation (2) above are summarized in Tables 11 and 12 below. These equations were then applied in ArcGIS to the colour-processed MS images of the validation samples to recover per-pixel per-waveband spectral reflectance and then compared to the values obtained using ASTM E903-12 [67].

Table 11. EL2 equations from Dulux targets and calibration bracket per camera waveband.

\begin{tabular}{cccc}
\hline Item & \%R-Green & \%R-Red $_{\boldsymbol{\lambda}}$ & \%R-NIR $_{\boldsymbol{\lambda}}$ \\
\hline Intercept & 7.7353 & 5.7211 & 7.1711 \\
Slope & 0.3202 & 0.3846 & 0.3866 \\
EL2 Dulux $\lambda$ & $\% \mathrm{R}_{\mathrm{G} \lambda}=7.7353+0.3202\left(\mathrm{DN}_{\mathrm{B}}\right)$ & $\% \mathrm{R}_{\mathrm{R} \lambda}=5.7211+0.3846\left(\mathrm{DN}_{\mathrm{G}}\right)$ & $\%_{\mathrm{NIR} \lambda}=7.1711+0.3866\left(\mathrm{DN}_{\mathrm{R}}\right)$ \\
\hline
\end{tabular}

Table 12. EL2 equations from Spectralon targets and calibration bracket per camera waveband.

\begin{tabular}{cccc}
\hline Item & \%R-Green & \%R-Red & \%R-NIR $_{\boldsymbol{\lambda}}$ \\
\hline Intercept & 6.7622 & -8.4403 & -5.1695 \\
Slope & 0.0102 & 0.4517 & 0.4487 \\
EL2 2 Spectralon $\lambda$ & $\ln \left(\% R_{\mathrm{G} \lambda}\right)=\ln (6.7622)+0.0102\left(\mathrm{DN}_{\mathrm{B}}\right)$ & $\% \mathrm{R}_{\mathrm{R} \lambda}=0.4517\left(\mathrm{DN}_{\mathrm{G}}\right)-8.4403$ & $\% \mathrm{R}_{\mathrm{NIR} \lambda}=0.4487\left(\mathrm{DN}_{\mathbf{R}}\right)-5.1695$ \\
\hline
\end{tabular}

\subsection{Validation Using Material Samples of Known Reflectance Values}

\subsubsection{Part 1: Validation Sample Image Acquisition and Reflectance Measurement}

To validate the EL equations, 13 samples of common building materials were used to compare spectrophotometer-measured [67] spectral reflectance values with reflectance quantities recovered from the EL2 equations.

Plywood-mounted material validation samples, several full-size samples of the same materials and two calibration brackets were placed vertically on a horizontal ledge adjacent a sun-exposed building wall (Figure 7).

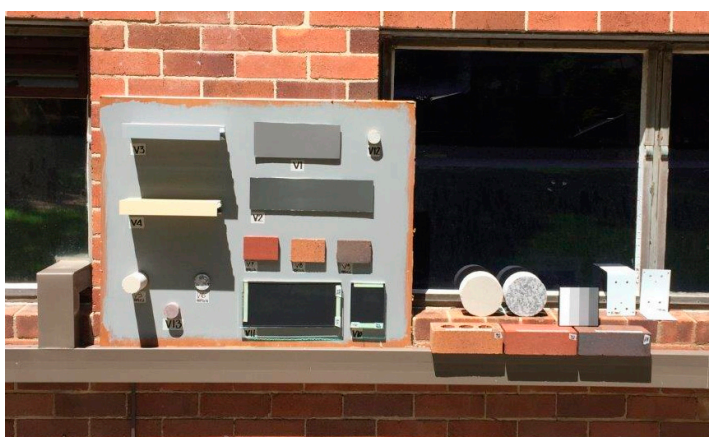

Figure 7. Plywood-mounted and full size validation samples and CBs.

Multispectral images were taken of the validation samples outdoors under clear-sky conditions on 9 February 2017 between 12:00 and 12:15 p.m. The solar altitude and solar azimuth at 12:10 p.m. were $66^{\circ} 32^{\prime} 25^{\prime \prime}$ and $38^{\circ} 27^{\prime} 47^{\prime \prime}$ respectively at $33^{\circ} 55^{\prime} 00^{\prime \prime}$ south latitude and $151^{\circ} 13^{\prime} 00^{\prime \prime}$ east longitude [131]. Images were taken normal to the calibration samples at a distance of $2.9 \mathrm{~m}$. The target sizes satisfied the recommendations in the literature [88] (Table 13).

Table 13. Validation sample target distance and IFOV to satisfy minimum target size requirements.

\begin{tabular}{cccccc}
\hline Target & Target Size & Distance & Sensor IFOV $^{\mathbf{1}}$ & Min. $\mathbf{3} \times$ IFOV & Min. 10 $\times$ IFOV \\
\hline Various & $45 \mathrm{~mm}(\mathrm{~min})$ & $2.9 \mathrm{~m}$ & $1.16 \mathrm{~mm}$ & $3.48 \mathrm{~mm}$ & $11.6 \mathrm{~mm}(<45 \mathrm{~mm})$ \\
\hline \multicolumn{5}{c}{${ }^{1}$ IFOV calculated from FOV optical calculator in Tetracam PW2 software. }
\end{tabular}


The validation samples had a wide range (approx. $7 \%$ to $78 \%$ ) of mean spectral reflectance values measured using a Perkins Elmer Lambda 1050 UV/VIS/NIR spectrophotometer over a 250-2500 nm range at $2.5 \mathrm{~nm}$ intervals with a $150 \mathrm{~mm}$ integrating sphere calibrated with a $99 \%$ Spectralon certified reflectance standard compliant with Reference [67] (Table 14 and Figure 8).

Table 14. Material validation sample ID and measured mean spectral reflectance values ${ }^{1}$.

\begin{tabular}{|c|c|c|c|c|c|}
\hline ID & Name & Description & $\% R-G_{\lambda}$ & $\% \mathbf{R}-\mathbf{R}_{\lambda}$ & $\%$ R-NIR ${ }_{\lambda}$ \\
\hline V1 & Colorbond "Windspray" & Factory painted steel sheet & 19.2386 & 22.5158 & 40.7007 \\
\hline $\mathrm{V} 2$ & Colorbond "Woodland Grey" & Factory painted steel sheet & 12.1960 & 13.1979 & 28.8771 \\
\hline V3 & Natural anodized aluminium & $45 \times 300 \mathrm{~mm}$ door frame profile & 71.3176 & 70.5578 & 67.4945 \\
\hline V4 & Powder-coated aluminium ("Cream") & $45 \times 300 \mathrm{~mm}$ door frame profile & 75.2613 & 77.9694 & 75.3959 \\
\hline V5 & Sydney sandstone (beige) & $140 \mathrm{~mm}$ (diam.) core sample & 55.6602 & 60.2846 & 65.5658 \\
\hline V6 & Granite stone (white \& grey colour) & 140 mm (diam.) core sample & 39.1646 & 38.8916 & 39.8336 \\
\hline V7 & PGH dry-pressed brick "McGarvie Red" & Clay brick biscuit $76 \times 110 \mathrm{~mm}$ & 13.5092 & 25.1807 & 32.5668 \\
\hline V8 & PGH dry-pressed brick "Copper Glow" & Clay brick biscuit $76 \times 110 \mathrm{~mm}$ & 21.4442 & 33.9654 & 39.2103 \\
\hline V9 & PGH dry-pressed brick "Mowbray Blue" & Clay brick biscuit $76 \times 110 \mathrm{~mm}$ & 12.1330 & 14.0271 & 17.6589 \\
\hline V10 & $6.38 \mathrm{~mm}$ (th) clear laminated glass & Clear glass on black backing & 8.8608 & 8.2229 & 7.1488 \\
\hline V11 & $5.0 \mathrm{~mm}(\mathrm{th})$ clear glass & Clear glass on black backing & 8.7144 & 8.2300 & 7.4313 \\
\hline V12 & Cement aggregate (white) & $45 \mathrm{~mm}$ (diam.) core sample & 49.3766 & 49.5922 & 47.8815 \\
\hline V13 & Granite stone (red) & $50 \mathrm{~mm}$ (diam.) core sample & 18.2971 & 21.6636 & 20.0889 \\
\hline
\end{tabular}

${ }^{1}$ Mean spectral reflectance values over ADC camera bandwidths.

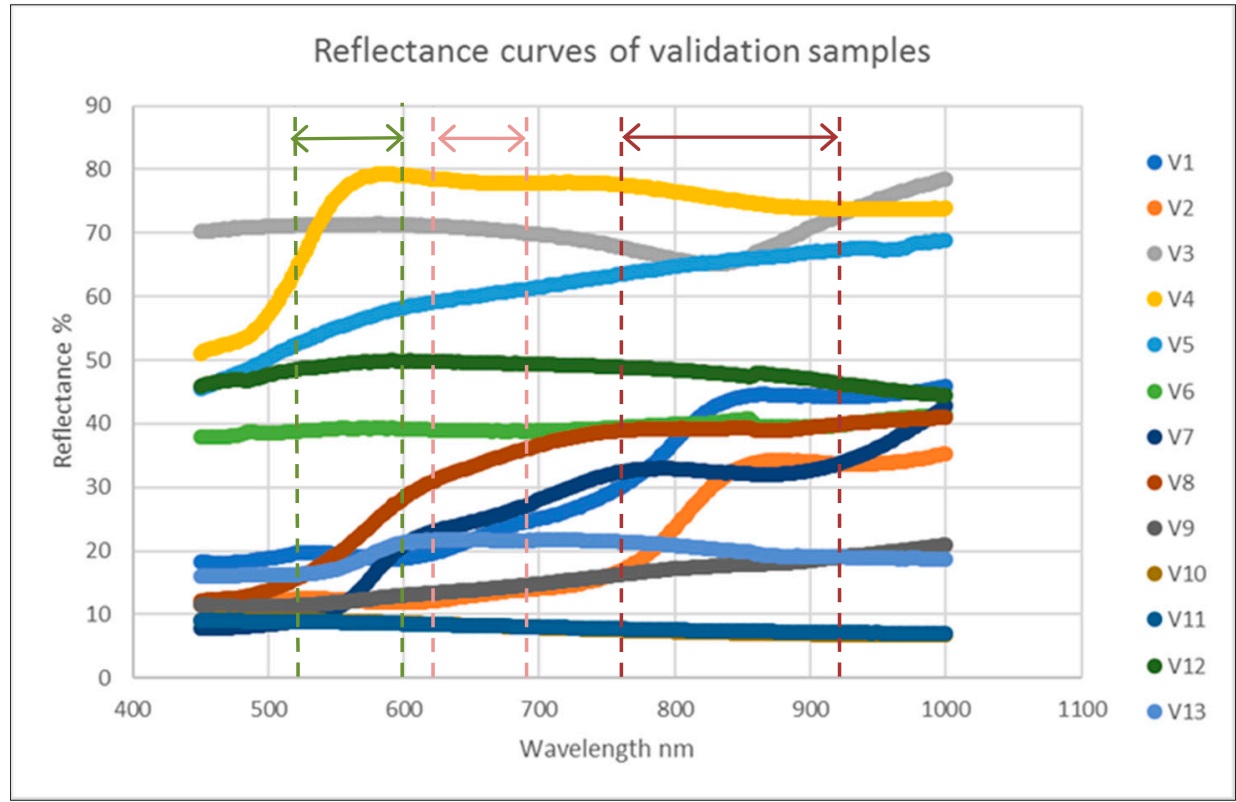

Figure 8. Validation samples reflectance curves $450-1000 \mathrm{~nm}$ at $2.5 \mathrm{~nm}$ intervals.

\subsubsection{Part 2: Reflectance Recovery from MS Images in ArcMap}

The multispectral images of the validation samples were pre-processed in accordance with the method previously outlined. The colour-processed images were imported in JPEG format into ArcMap for further processing. Discrete ROI raster files were created for each material sample (from a composite image) using the "Clip" function in ArcMap. These files were used as inputs into a raster algebra expression of the empirical line equations (EL2 from Tables 11 and 12) to create spectral reflectance raster files per waveband.

\section{Results}

The measured $(\mathrm{M})$ and predicted $(\mathrm{P})$ mean spectral reflectance values of the 13 validation samples for all camera wavebands using the Dulux-derived EL2 are shown in Table 15 below. Common statistical measures of correlation (Pearson's $r$ and Spearman's rho), predictive precision (coefficient 
of determination, $\mathrm{R}^{2}$ ), distribution difference (Mann-Whitney's $U$ test) and prediction accuracy (Willmott's index of agreement $d$, root mean square (RMSE) and mean absolute error (MAE)) are shown in Table 16 for evaluation of model performance $[128,129,137]$ based on the OLS regression of measured against EL2-predicted reflectance values [138].

Table 15. Measured (M) and EL2-predicted (P) mean spectral reflectance (\%) of 13 validation samples using EL1 $1_{\text {Dulux }}$ intercept.

\begin{tabular}{cccccccccc}
\hline Waveband & \multicolumn{3}{c}{ Green } & \multicolumn{3}{c}{ Red } & & \multicolumn{3}{c}{ NIR } \\
\hline Sample ID & $\mathbf{M}$ & $\mathbf{P}$ & $\mathbf{A R}^{\mathbf{1}}$ & $\mathbf{M}$ & $\mathbf{P}$ & AR & $\mathbf{M}$ & $\mathbf{P}$ & AR \\
\hline V1 & 19.237 & 37.778 & 18.541 & 22.516 & 28.898 & 6.382 & 40.701 & 52.101 & 11.400 \\
V2 & 12.196 & 27.145 & 14.949 & 13.198 & 17.670 & 4.472 & 28.877 & 39.703 & 10.826 \\
V3 & 71.318 & 70.411 & 0.907 & 70.558 & 62.952 & 7.606 & 67.495 & 59.313 & 8.182 \\
V4 & 75.261 & 69.702 & 5.560 & 77.969 & 91.490 & 13.521 & 75.396 & 90.843 & 15.447 \\
V5 & 55.660 & 62.596 & 6.936 & 60.285 & 62.741 & 2.456 & 65.566 & 61.489 & 4.077 \\
V6 & 39.165 & 44.223 & 5.058 & 38.892 & 42.304 & 3.412 & 39.834 & 41.017 & 1.184 \\
V7 & 13.509 & 26.531 & 13.022 & 25.181 & 34.055 & 8.874 & 32.567 & 36.513 & 3.946 \\
V8 & 21.444 & 32.155 & 10.710 & 33.965 & 40.947 & 6.981 & 39.210 & 41.689 & 2.479 \\
V9 & 12.133 & 20.282 & 8.149 & 14.027 & 19.200 & 5.173 & 17.659 & 22.848 & 5.189 \\
V10 & 8.861 & 19.832 & 10.971 & 8.223 & 13.064 & 4.841 & 7.149 & 29.292 & 22.143 \\
V11 & 8.714 & 20.409 & 11.694 & 8.230 & 11.781 & 3.551 & 7.431 & 33.470 & 26.039 \\
V12 & 49.377 & 64.151 & 14.775 & 49.592 & 62.009 & 12.416 & 47.882 & 52.978 & 5.097 \\
V13 & 18.297 & 39.395 & 21.098 & 21.664 & 42.434 & 20.771 & 20.089 & 35.495 & 15.406 \\
Mean & 31.167 & 41.124 & 10.952 & 34.177 & 40.734 & 7.728 & 37.681 & 45.904 & 10.108 \\
Sum AR & & & 142.37 & & & 100.46 & & & 131.41 \\
RMSE ${ }^{1}$ & & & 12.228 & & & 9.177 & & & 12.561 \\
$d^{1}$ & & & 0.920 & & & 0.960 & & & 0.892 \\
\hline
\end{tabular}

${ }^{1}$ AR: absolute residual. RMSE and $d$ from [129].

Table 16. Rank correlation and OLS regression statistics M-P from Table 15 data.

\begin{tabular}{|c|c|c|c|c|c|c|}
\hline \multirow{2}{*}{$\begin{array}{c}\text { Statistic } \\
\text { Rank Correlation }\end{array}$} & \multicolumn{2}{|c|}{ Green } & \multicolumn{2}{|c|}{ Red } & \multicolumn{2}{|c|}{ NIR } \\
\hline & & & & & & \\
\hline Mann-Whitney $U^{1}$ & $U_{c}=45$ & $U=54$ & $U_{c}=45$ & $U=69$ & $U_{c}=45$ & $U=64$ \\
\hline Test result & & $U>U_{c}$ & & $U>U_{c}$ & & $U>U_{c}$ \\
\hline Z-score & 1.53846 & & 0.76923 & & 1.02564 & \\
\hline p-value & 0.12356 & & 0.4413 & & 0.30302 & \\
\hline Spearman's rho $\left(r_{s}\right)$ & 0.945 & & 0.940 & & 0.967 & \\
\hline \multicolumn{7}{|l|}{ OLS regression M-P } \\
\hline RMSEs $^{1}$ & 5.993 & & 6.346 & & 9.261 & \\
\hline MAE & 4.893 & & 4.188 & & 8.092 & \\
\hline Pearson's $r$ & 0.966 & & 0.960 & & 0.900 & \\
\hline $\mathrm{R}^{2}$ & 0.933 & & 0.922 & & 0.810 & \\
\hline$d$ & 0.982 & & 0.979 & & 0.945 & \\
\hline Intercept (a) & -18.372 & & -4.81 & & -13.878 & \\
\hline Slope (b) & 1.2046 & & 0.9224 & & 1.1232 & \\
\hline
\end{tabular}

Plots of the measured and Dulux EL2 equation-predicted mean spectral reflectance values of the 13 validation samples are shown in Figures 9 and 10 below.

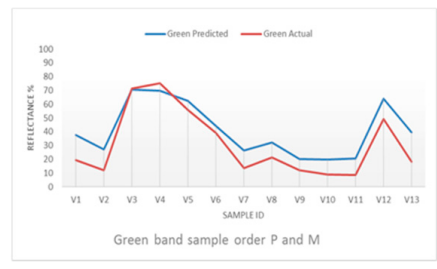

(a)

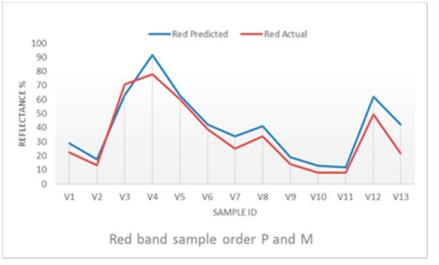

(b)

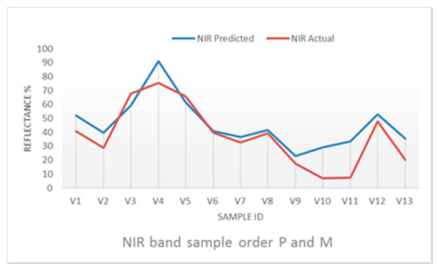

(c)

Figure 9. $\mathrm{M}$ (red line) and P reflectance plots for G (a); R (b) and NIR (c) bands from EL2 ${ }_{\text {Dulux }}$. 


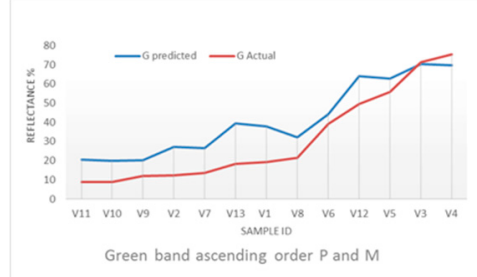

(a)

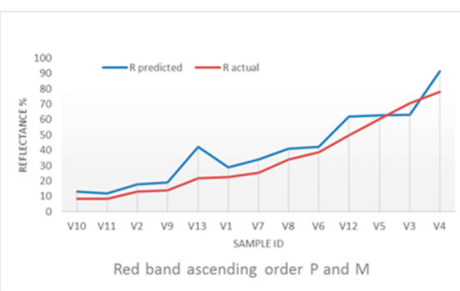

(b)

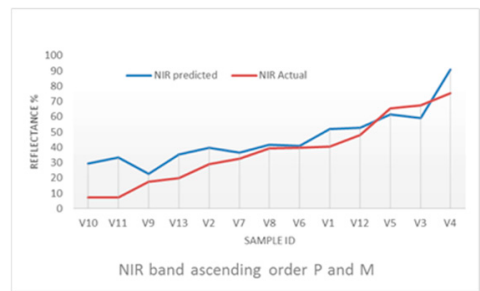

(c)

Figure 10. Ascending order $M$ (red line) and P reflectance plots for G (a); R (b) and NIR (c) bands from EL2 2 Dulux.

The OLS plots of measured $(\mathrm{M})$ regressed against predicted $(\mathrm{P})$ reflectance values per camera waveband are shown in Figure 11 below.

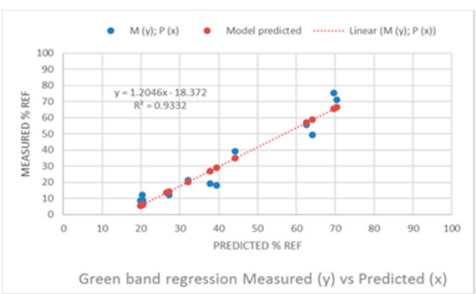

(a)

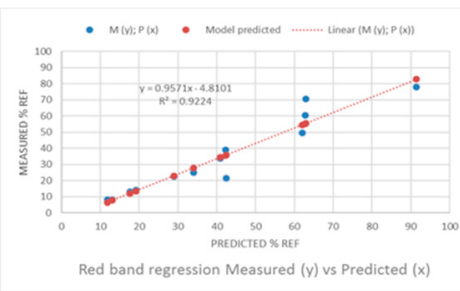

(b)

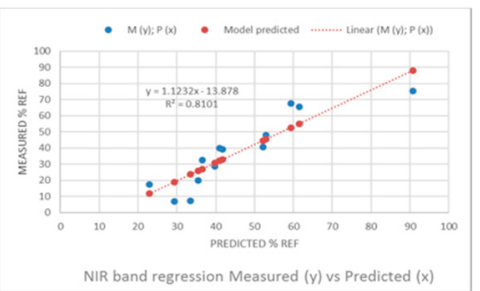

(c)

Figure 11. OLS regression of $M$ against $P$ reflectance per sample for $G(\mathbf{a})$; Red (b) and NIR (c) from EL2 Dulux.

The measured and predicted mean spectral reflectance values of the 13 validation samples for the three camera wavebands using the intercept value from the Spectralon-derived EL2 equation and prediction model evaluation statistics are shown in Tables 17 and 18 below.

Table 17. Measured (M) and EL2-predicted (P) mean spectral reflectance (\%) of 13 validation samples

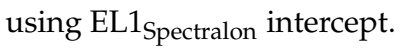

\begin{tabular}{cccccccccc}
\hline Waveband & \multicolumn{3}{c}{ Green } & \multicolumn{3}{c}{ Red } & \multicolumn{3}{c}{ NIR } \\
\hline Sample ID & $\mathbf{M}$ & $\mathbf{P}$ & AR & $\mathbf{M}$ & $\mathbf{P}$ & AR & $\mathbf{M}$ & $\mathbf{P}$ & AR \\
\hline V1 & 19.237 & 17.527 & 1.712 & 22.516 & 12.275 & 10.241 & 40.701 & 46.276 & 5.576 \\
V2 & 12.196 & 12.512 & 0.315 & 13.198 & -3.218 & 16.416 & 28.877 & 29.583 & 0.705 \\
V3 & 71.318 & 49.314 & 22.003 & 70.558 & 59.251 & 11.307 & 67.495 & 55.987 & 11.507 \\
V4 & 75.261 & 48.218 & 27.043 & 77.969 & 98.619 & 20.649 & 75.396 & 98.442 & 23.046 \\
V5 & 55.660 & 38.494 & 17.166 & 60.285 & 58.960 & 1.325 & 65.566 & 58.917 & 6.649 \\
V6 & 39.165 & 21.499 & 17.665 & 38.892 & 30.768 & 8.124 & 39.834 & 31.352 & 8.481 \\
V7 & 13.509 & 12.270 & 1.239 & 25.181 & 19.389 & 5.792 & 32.567 & 25.287 & 7.280 \\
V8 & 21.444 & 14.665 & 6.779 & 33.965 & 28.896 & 5.070 & 39.210 & 32.257 & 6.953 \\
V9 & 12.133 & 10.065 & 2.068 & 14.027 & -1.103 & 15.130 & 17.659 & 6.887 & 10.772 \\
V10 & 8.861 & 9.922 & 1.062 & 8.223 & -9.568 & 17.791 & 7.149 & 15.564 & 8.415 \\
V11 & 8.714 & 10.106 & 1.391 & 8.230 & -11.338 & 19.568 & 7.431 & 21.190 & 13.759 \\
V12 & 49.377 & 40.439 & 8.938 & 49.592 & 57.950 & 8.358 & 47.882 & 47.458 & 0.424 \\
V13 & 18.297 & 18.448 & 0.152 & 21.664 & 30.948 & 9.284 & 20.089 & 23.916 & 3.827 \\
Mean & 31.167 & 23.345 & 8.272 & 34.177 & 28.602 & 11.465 & 37.681 & 37.932 & 8.262 \\
Sum AR & & & 142.37 & & & 100.46 & & & 131.41 \\
RMSE & & & 12.228 & & & 9.177 & & & 12.561 \\
$d$ & & & 0.920 & & & 0.960 & & & 0.892 \\
\hline
\end{tabular}


Table 18. Rank correlation and OLS regression statistics M-P from Table 17 data.

\begin{tabular}{|c|c|c|c|c|c|c|}
\hline Statistic & \multicolumn{2}{|c|}{ Green } & \multicolumn{2}{|c|}{ Red } & \multicolumn{2}{|c|}{ NIR } \\
\hline \multicolumn{7}{|l|}{ Rank correlation } \\
\hline Mann-Whitney $U^{1}$ & $U_{c}=45$ & $U=73$ & $U_{c}=45$ & $U=70$ & $U_{c}=45$ & $U=80$ \\
\hline Test result & & $U>U_{c}$ & & $U>U_{c}$ & & $U>U_{c}$ \\
\hline Z-score & 0.5641 & & 0.71795 & & 0.20513 & \\
\hline p-value & 0.57548 & & 0.47152 & & 0.83366 & \\
\hline Spearman's $r h o\left(r_{s}\right)$ & 0.945 & & 0.940 & & 0.967 & \\
\hline \multicolumn{7}{|l|}{ OLS regression M-P } \\
\hline RMSEs & 4.648 & & 6.346 & & 9.261 & \\
\hline MAE & 3.442 & & 4.188 & & 8.092 & \\
\hline Pearson's $r$ & 0.979 & & 0.960 & & 0.900 & \\
\hline $\mathrm{R}^{2}$ & 0.960 & & 0.922 & & 0.810 & \\
\hline$d$ & 0.989 & & 0.979 & & 0.945 & \\
\hline Intercept (a) & -5.475 & & 14.332 & & 6.039 & \\
\hline Slope (b) & 1.5696 & & 0.6938 & & 0.8342 & \\
\hline
\end{tabular}

${ }^{1} U$ test: no statistical difference in distributions at $95 \%$ confidence level.

Plots of the measured and Spectralon EL2 equation-predicted mean spectral reflectance values of the 13 validation samples are shown in Figures 12 and 13 below.

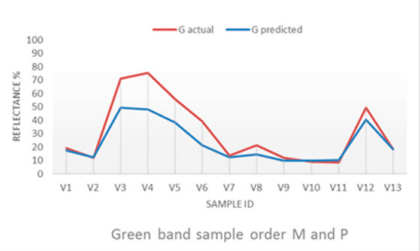

(a)

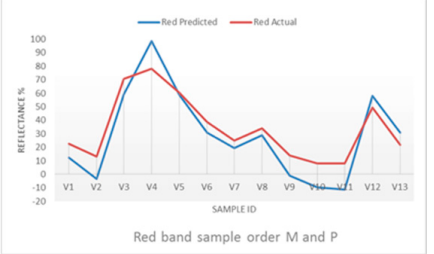

(b)

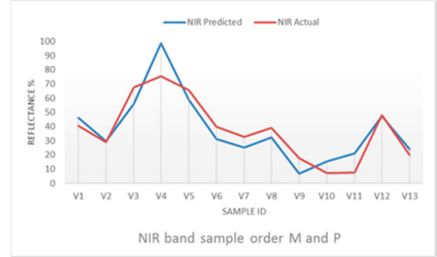

(c)

Figure 12. $M$ (red line) and P reflectance plots for $G(\mathbf{a}) ; R(\mathbf{b})$ and NIR (c) bands from EL2 ${ }_{\text {Spect }}$.

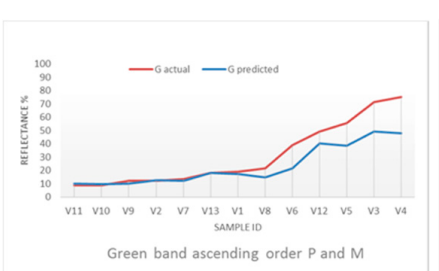

(a)

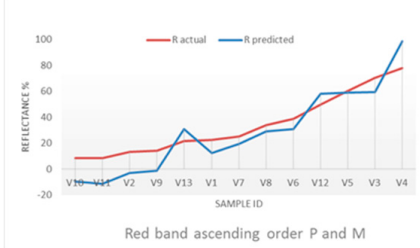

(b)

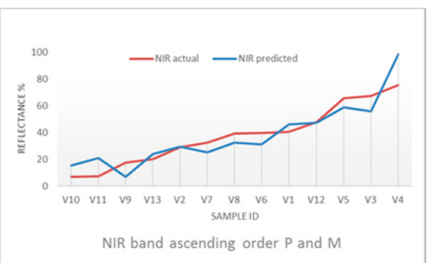

(c)

Figure 13. Ascending order $M$ (red line) and P plots for G (a); R (b) and NIR (c) bands from EL2spect.

The OLS plots of measured $(\mathrm{M})$ regressed against predicted $(\mathrm{P})$ reflectance values per camera waveband are shown in Figure 14 below.

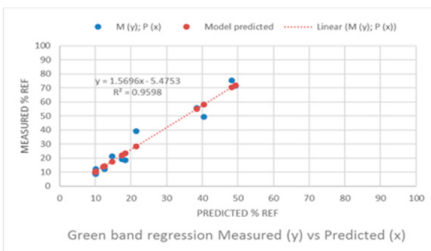

(a)

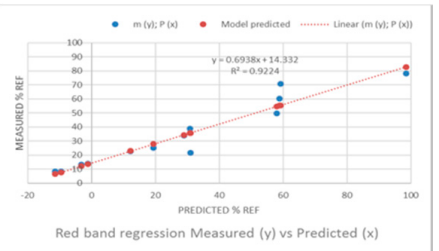

(b)

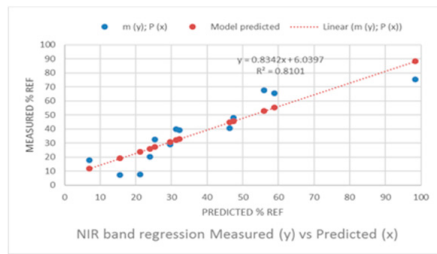

(c)

Figure 14. OLS regression of $M$ against $P$ reflectance per sample for G (a); Red (b) and NIR (c) from EL2 ${ }_{\text {Spect }}$. 
In addition to linear covariance tests $\left(r, R^{2}\right.$, intercept a and slope $\left.b\right)$, OLS model prediction error was evaluated using supplementary measures recommended by [128,129]. These include the systematic root mean square error (RMSEs) and the unsystematic root mean square error (RMSEu). For "good" model performance the RMSE should be low, RMSEs should tend to zero, RMSEu should approach RMSE and Willmott's index of agreement (d), a measure of prediction accuracy, should approach unity [128]. MAE provides an estimate of mean differences between measured and predicted values and is an "intuitive", reliable measure of average model prediction error [139]. While RMSE is a widely reported measure of average model error, it is less reliable than MAE since it exaggerates differences due to higher sensitivity of RMSE to outliers $[129,140]$ and due to the inconsistent variance of RMSE with average error [139]. Table 19 below summarizes the performance of both models per waveband to evaluate the most accurate and precise predictive EL equations.

Table 19. Summary statistics of EL2-equations and OLS model performance.

\begin{tabular}{|c|c|c|c|c|c|c|c|c|c|c|c|c|}
\hline \multirow[t]{2}{*}{ Equations } & \multicolumn{4}{|c|}{ EL2-Equation Measures } & \multicolumn{4}{|c|}{ OLS Regression Parameters } & \multicolumn{4}{|c|}{ OLS Difference Measures } \\
\hline & ${ }^{1} \mathbf{M}_{m}$ & ${ }^{1} \mathbf{P}_{m}$ & RMSE & MAE & $r$ & $\mathbf{R}^{2}$ & $a$ & $b$ & RMSE $_{\mathrm{S}}$ & $\mathrm{RMSE}_{\mathbf{u}}$ & MAE & $d$ \\
\hline Green $_{\text {Dulux }}$ & 31.167 & 41.124 & 12.228 & 10.952 & 0.966 & 0.933 & -18.372 & 1.205 & 5.993 & 10.659 & 4.893 & 0.982 \\
\hline Green $_{\text {Spectralon }}$ & 31.167 & 23.345 & 12.279 & 8.272 & 0.979 & 0.960 & -5.475 & 1.570 & 4.649 & 11.364 & 3.442 & 0.989 \\
\hline $\operatorname{Red}_{\text {Dulux }}$ & 34.177 & 40.734 & 9.177 & 7.728 & 0.960 & 0.922 & -4.81 & 0.922 & 6.346 & 6.630 & 4.188 & 0.979 \\
\hline Red $_{\text {Spectralon }}$ & 34.177 & 28.602 & 12.830 & 11.465 & 0.960 & 0.922 & 14.332 & 0.6938 & 6.346 & 11.151 & 4.188 & 0.979 \\
\hline NIR $_{\text {Dulux }}$ & 37.681 & 45.904 & 12.561 & 10.108 & 0.900 & 0.810 & -13.878 & 1.123 & 9.261 & 8.486 & 8.092 & 0.945 \\
\hline $\mathrm{NIR}_{\text {Spectralon }}$ & 37.681 & 37.932 & 10.014 & 8.262 & 0.900 & 0.810 & 6.038 & 0.834 & 9.261 & 3.810 & 8.092 & 0.945 \\
\hline
\end{tabular}

Comparing the model results for the Green waveband, the lower Spectralon-derived OLS equation RMSEs and MAE, higher RMSEu with higher $\mathrm{d}$ in agreement with higher regression $\mathrm{R}^{2}$ indicate its unambiguous predictive superiority (bold in Table 19). Comparing the model results for the Red waveband, considering equivalence of linear regression measures RMSEs, MAE and $d$, the lower Dulux-derived EL2-equation MAE (lowest of all wavebands) and regression parameters (intercept a (-4.81) and slope $\mathrm{b}(0.922)$ ) closer to the ideal 1:1 correspondence line (when $\mathrm{a}=0$ and, more importantly, $\mathrm{b}=1$ ) for goodness of fit [141] indicate its superior predictive precision and accuracy (bold in Table 19). The above interpretation was supported when comparing the additive and proportional components [128] of the MSEs for each model.

Comparing the results for the NIR waveband, despite a lower MAE for the EL2-Spectralon equation estimates and considering the equivalence of OLS correlation and difference measures, the significantly lower RMSEu for Spectralon-derived OLS suggests that the Dulux-derived EL2 equation contains proportionally less systematic error overall and hence improved accuracy (bold in Table 19). This conclusion is augmented by computation of the ratio MSEs/MSE [129] that indicates that the Dulux-derived NIR predictive model contains a significantly lower proportion (54.4\% vs. $85.5 \%$ ) of systematic error and hence greater comparative model accuracy.

In summary, the optimal predictive models per waveband indicate a strong monotonic agreement $(0.940$ < Spearman's Rho > 0.967) and linear association $(0.900<$ Pearson's $r>0.966)$ between the measured and EL2-predicted reflectance values that confirm a near-perfect positive agreement between pairs of samples of ranked scores and a strong linear correlation [142]. The regression measures imply distribution near-equivalence and high confidence in trend predictions [143]. Regardless of the residual magnitudes, the distributions (Figures 9, 10, 12 and 13) show a strong positive agreement that supports reflectance predictions on a relative (high/low) scale. The non-parametric Mann-Whitney U-test for difference between two independent groups exhibits no statistically significant difference in distributions at the $95 \%$ confidence level, reinforcing the above interpretation [144]. The coefficients of determination $\left(\mathrm{R}^{2}\right)$ of the OLS models for all wavebands exceed $81 \%$ (NIR). Green and Red band $\mathrm{R}^{2}$ exceed $92.2 \%$. This suggests stronger agreement in the visible bands between measured and predicted values and higher confidence in the precision of the linear covariance between measured and predicted values [138]. 
Comparative Assessment of Measured and EL2 Predicted Reflectance Distributions

The mean bias error (MBE) [139] between measured and Dulux-derived EL2 equation predicted reflectance values for all wavebands indicates a systematic overestimation of measured values (Figures 9 and 10), a trend corroborated by the regression model (Figure 11) and regression slope and intercept parameters (Table 16). The overestimation bias derives from the camera calibration model (Table 6). However, higher reflectance samples (V3 (nominal reflectance 70\%); V4 (75\%) and V5 (60\%) in Table 15) underestimate measured values. Underestimation of high-albedo surfaces by the EL method has been reported previously [94]. Sample V13, red Granite stone (nom. reflectance $20 \%$ ) exhibits the largest absolute residual for the Green and Red wavebands. The high error may be theoretically accounted for by the reflectance anisotropy common to natural materials [135] in combination with artifacts of the prediction model. However, the low absolute residual magnitude of the Spectralon-derived estimate for the same sample (Table 17) implicates the latter. The largest absolute residual for the NIR waveband (Dulux-derived) occurs for sample V11, $5 \mathrm{~mm}$ Clear Glass (nom. reflectance 8\%). The specular behaviour of glass at oblique incident angles (as occurred in the validation experiment, where the solar altitude exceeded $65^{\circ}$ ) may account for the larger difference in the NIR region [48]. Further, the low measured reflectance of glass falls outside the reflectance data range used to build the EL equations which may increase prediction error for this sample [98].

The MBE between measured and Spectralon-derived EL2 equation predicted reflectance values for the Green and Red wavebands indicates a systematic underestimation of measured values (Figures 12 and 13), a trend corroborated by the regression model (Figure 14) and regression slope and intercept parameters (Table 18). The underestimation bias derives from the camera calibration model (Table 7). MBE for the NIR waveband indicates marginal average overestimation of measured reflectance values, with some exceptions. Sample V13, red granite stone, is overestimated in all three wavebands and largest for the Red waveband. The highest reflectance sample, Sample V4 (powder coated aluminium, cream colour, nominal reflectance $75 \%$ ), exhibits the largest absolute residual for all camera wavebands and is overestimated in the Red and NIR bands. The Spectralon model prediction of maximum error per sample is inconsistent with the Dulux-derived response to maximum error but consistent with prior studies that found predictions of high albedo surfaces have higher errors than low albedo surfaces [48].

The range of measured mean spectral reflectance values (approx. $7 \%$ to $78 \%$ ) of the validation samples across all wavebands was comfortably within the upper reflectance limit of the calibration targets used in the development of the predictive equations (approx. 99\% for EL1 and 89\% for EL2). However, the two glass samples had measured reflectance values below the lower limit of the model data range (approx. $12 \%$ for EL1). For all samples (excluding glass) the predicted values were interpreted within the limits of the calibration equations $[88,98]$.

\section{Discussion}

In this study a terrestrial application of the EL method [88] was developed to radiometrically calibrate and validate close-range remotely sensed images of vertical surface materials obtained from a narrow FOV MS camera using a single in-situ calibration target [98]. The y-intercept of the camera response function, although variable with camera calibration target properties, was shown to be the minimum reflectance detectable by the camera sensor per waveband and was used as the lower data point. The second coordinate of the EL equation was derived from the per-waveband spectral reflectance values and DNs of the CB. While the CB was assumed to be Lambertian, the spectrophotometer measurements of the CB indicated that mean spectral reflectance was unequal across sensor wavebands (Table 9) with a declining reflectance trend observed from shorter (visible) to longer (NIR) wavelengths (Figure 6) necessitating a separate EL equation for each waveband [98]. The optimal EL2 equations per waveband (Table 19) strongly linearly correlated $(0.900<\mathrm{r}>0.979)$ per-pixel spectral reflectance to image $\mathrm{DNs}$ with absolute prediction accuracies $(7.728 \%<$ MAE $>10.108 \%)$ within the range reported in the literature $[88,94]$.

Theoretically, improvements in accuracy are achievable if the calibration target is accurately characterized [136] and more than one in-situ calibration target is used [132] and future experimental 
design could, without much logistical effort, incorporate additional portable near-Lambertian targets, selected for spectral uniformity within sensor wavebands [135]. Instrument characteristics have been identified as a common source of experimental uncertainty [145]. Accuracy improvements may result from the optimisation of camera settings (i.e., manual exposure) within the limitations of the sensor radiometric resolution [92,98,134] and from corrections for sensor background noise and vignetting [87]. However, the anticipated absolute accuracy improvements are not crucial for the "relative magnitude" of elements of the scene approach adopted here where distribution equivalence is more highly prized.

The variable per-waveband mean spectral reflectance of the $C B$, characterized by greater reflectance in the visible band (Table 9), its smooth, low-sheen surface finish (potentially with a non-negligible specular component at large incident angles $[48,146]$ ) and the non-uniform Tetracam ADC CMOS sensor response function to different sensor bandwidths (with lowest sensitivity in the Green waveband) may account for the relative distribution of errors per waveband [86,87]. Importantly, due to near-horizontal viewing geometry, it is speculated that the accuracy of the reflectance recovery computations is strongly influenced by angular and adjacency effects (in particular from ground reflections) $[75,85]$ and the impacts of in-situ spectral, diffuse and direct effects that are not explicitly accounted for in the laboratory measurements $[62,146,147]$.

The majority of prior ground- or UAV-based studies utilising the vicarious EL method with narrow FOV MS sensors for reflectance recovery have been concerned with horizontal vegetated surfaces $[86,87,95,96,102]$ and fewer with horizontal urban surfaces $[48,104]$. Furthermore, the use of the EL method applied to terrestrial close-range MS sensors with near-horizontal viewing geometry of urban building facades has not been previously reported. However, there is growing interest in the use of ground-based, close range narrow FOV sensors for retrieval of the spatio-temporal optical and thermal characteristics of vertical surfaces at the facet and sub-facet scales for building damage assessment [148], geological surveys [85] and urban climatology [78].

As there is a gap in the literature addressing, and no standard method exists for, facet and sub-facet scale terrestrial reflectance recovery from real building facades, the value of this paper is its contribution to the development of a logistically simple, replicable, validated reflectance recovery method, with explicit error magnitude and source estimation, suitable for climatology studies of building facades using a single mobile calibration target and high-resolution close-range images obtained from a relatively low-cost MS camera. However, since each camera has a unique sensor response-function [92] and irradiance may vary under different environmental conditions, the determination of the relationship between reflectance and DNs necessitates the computation of new equations for each new sensor and every unique environment [98].

\section{Conclusions}

This paper described a novel application of the EL method for radiometric calibration of a relatively low-cost MS sensor applied to close-range images of vertical urban surface materials. The performance of the single-target EL calibration equations was evaluated and quantified using validation samples of common building materials. Confidence in the precision and accuracy of the EL equations per-waveband was assessed using covariance statistics and error measures $[128,129,137]$ and absolute prediction accuracies $(7.728 \%<$ MAE $>10.108 \%)$ were within the range reported in the literature $[88,94,149]$ and above prediction accuracies $(15-20 \%)$ reported for single-target calibration methods [88,103].

Based on the optimum equations (Table 19) the results are encouraging and indicate that the prediction equations (Tables 11 and 12) satisfactorily characterize the per waveband reflectance differences of commonly used materials found on Australian building facades. For example, dry-pressed clay bricks (samples V7, V8, and V9, Table 14) are frequently used in low to medium-rise construction of residential buildings in Sydney and are satisfactorily predicted in the green waveband within a range of $1.24 \%$ to $6.68 \%$ absolute error (AE) (Table 17) and OLS model absolute residuals (OMAR) of $0.27 \%, 3.9 \%$ and $1.8 \%$ respectively. Importantly, the NIR waveband reflectance values are 
satisfactorily predicted within a range of $2.48 \%$ to $5.19 \%$ AE (Table 15 ) and OMAR in the range of $5.4 \%$ to $6.2 \%$. This relative predictive strength is significant since dry-pressed clay bricks are both pervasive and more reflective in the NIR region (Table 14 and Figure 8).

Dark-grey pre-painted steel sheeting (sample V2) is another prevalent material used for building facade cladding that is more reflective in the NIR region (Table 14 and Figure 8). Green and NIR waveband reflectance values are satisfactorily predicted with a $0.32 \%$ and $0.71 \%$ AE (Table 17 ) and OMAR of $1.96 \%$ and $1.84 \%$ respectively. Glass (samples V10 and V11) is reasonably well predicted in the visible spectrum with a $1.06 \%$ and $4.84 \%$ AR in the Green (Table 17) and Red (Table 15) bands with an OMAR of $1.24 \%$ and $0.53 \%$ respectively for sample V10.

While the results confirm the findings of prior studies supporting the utility of a single in-situ target for radiometric calibration $[86,98]$ it may be concluded from method and model evaluation that improvements in measurement protocols and calibration target specification would reduce prediction model error, although the anticipated absolute accuracy improvements are not warranted here since the "relative magnitude" of elements of the scene and distribution equivalence are desired for the development of a larger statistical model. The regression statistics (Tables 16, 18 and 19) imply distribution near-equivalence between measured and predicted reflectance values and high confidence in trend predictions. This demonstrates that a single-target EL method can be applied to recover spectral reflectance from terrestrial close-range MS images of vertical surfaces with satisfactory results.

Author Contributions: Conceptualization; Methodology; Validation; Formal Analysis; Investigation; Writing-Original Draft Preparation; Writing-Review \& Editing and Funding Acquisition, J.F.; Resources; Funding Acquisition; WritingReview \& Editing; Supervision, P.O.; Resources; Supervision and Funding Acquisition, A.P.

Funding: This research was funded by the Cooperative Research Centre (CRC) for Low Carbon Living, project number RP2005, and the Australian Government Research Training Program (RTP) Scholarship.

Acknowledgments: The authors wish to acknowledge Bill Joe, Research Support Engineer at the School of Material Science and Engineering, UNSW, and Alan Yee, Professional Officer at the School of Photovoltaics and Renewable Energy Engineering (SPREE), UNSW, for their technical support during the laboratory-based spectrophotometer measurements.

Conflicts of Interest: The authors declare no conflict of interest. The funders had no role in the design of the study; in the collection, analyses, or interpretation of data; in the writing of the manuscript, and in the decision to publish the results.

\section{References}

1. Oke, T.R. Boundary Layer Climates, 2nd ed.; Methuen: London, UK, 1987; ISBN 0-416-04422-0.

2. Oke, T.R. The energetic basis of the urban heat island. Q. J. R. Meteorol. Soc. 1982, 108, 1-24. [CrossRef]

3. He, B.-J. Potentials of meteorological characteristics and synoptic conditions to mitigate urban heat island effects. Urban Clim. 2018, 24, 26-33. [CrossRef]

4. Santamouris, M.; Haddad, S.; Fiorito, F.; Wang, R. Urban Heat Island and Overheating Characteristics in Sydney, Australia. An Analysis of Multiyear Measurements. Sustainability 2017, 9, 712. [CrossRef]

5. Oke, T.R.; Mills, G.; Christen, A.; Voogt, J.A. Urban Climates; Cambridge University Press: Cambridge, UK, 2017; ISBN 978-0-521-84950-0.

6. Oke, T.R. Towards a better scientific communication in urban climate. Theor. Appl. Climatol. 2006, 84, 179-190. [CrossRef]

7. Karimi, M.; Vant-Hull, B.; Nazari, R.; Mittenzwei, M.; Khanbilvardi, R. Predicting surface temperature variation in urban settings using real-time weather forecasts. Urban Clim. 2017, 20, 192-201. [CrossRef]

8. Doulos, L.; Santamouris, M.; Livada, I. Passive cooling of outdoor urban spaces. The role of materials. Sol. Energy 2004, 77, 231-249. [CrossRef]

9. Roth, M.; Oke, T.R.; Emery, W.J. Satellite-derived urban heat islands from three coastal cities and the utilization of such data in urban climatology. Int. J. Remote Sens. 1989, 10, 1699-1720. [CrossRef]

10. Stewart, I.D.; Oke, T.R. Local Climate Zones for Urban Temperature Studies. BAMS 2012, 93, $1879-1900$. [CrossRef] 
11. Santamouris, M. Innovating to zero the building sector in Europe: Minimising the energy consumption, eradication of the energy poverty and mitigating the local climate change. Sol. Energy 2016, 128, 61-94. [CrossRef]

12. Santamouris, M. Analyzing the heat island magnitude and characteristics in one hundred Asian and Australian cities and regions. Sci. Total. Environ. 2015, 512-513, 582-598. [CrossRef] [PubMed]

13. Mora, C.; Dousset, B.; Caldwell, I.R.; Powell, F.E.; Geronimo, R.C.; Bielecki, C.R.; Counsell, C.W.; Dietrich, B.S.; Johnston, E.T.; Louis, L.V.; et al. Global risk of deadly heat. Nat. Clim. Chang. 2017, 7, 501-506. [CrossRef]

14. Intergovernmental Panel on Climate Change (IPCC). Summary for policymakers. In Climate Change 2014: Impacts, Adaptation, and Vulnerabilit; Contribution of Working Group II to the Fifth Assessment Report of the Intergovernmental Panel on Climate Change; Cambridge University Press: Cambridge, UK, 2014.

15. Steffen, W.; Hughes, L.; Perkins, S. Heatwaves: Hotter, Longer, More Often; Climate Council of Australia: Sydney, Australia, 2014; ISBN 978-0-9924142-2-1.

16. Paravantis, J.; Santamouris, M.; Cartalis, C.; Efthymiou, C.; Kontoulis, N. Mortality associated with high ambient temperatures, heatwaves, and the urban heat island in Athens, Greece. Sustainability 2017, 9, 606. [CrossRef]

17. Heaviside, C.; Macintyre, H.; Vardoulakis, S. The urban heat island: Implications for health in a changing environment. Curr. Environ. Health Report 2017, 4, 296-305. [CrossRef] [PubMed]

18. Tan, J.; Zheng, Y.; Tang, X.; Guo, C.; Li, L.; Song, G.; Zhen, X.; Yuan, D.; Kalkstein, A.J.; Li, F. The urban heat island and its impact on heat waves and human health in Shanghai. Int. J. Biometeorol. 2010, 54, 75-84. [CrossRef] [PubMed]

19. Akbari, H.; Cartalis, C.; Kolokotsa, D.; Muscio, A.; Pisello, A.L.; Rossi, F.; Santamouris, M.; Synnefa, A.; Wong, N.H.; Zinzi, M. Local climate change and urban heat island mitigation techniques-The state of the art. J. Civ. Eng. Manag. 2016, 22, 1-16. [CrossRef]

20. Santamouris, M.; Kolokotsa, D. (Eds.) Urban Climate Mitigation Techniques; Routledge: New York, NY, USA, 2016; ISBN 978-0-415-71213-2.

21. Santamouris, M. Regulating the damaged thermostat of the cities-Status, impacts and mitigation strategies. Energy Build. 2015, 91, 43-56. [CrossRef]

22. Sun, T.; Kotthaus, S.; Li, D.; Ward, H.C.; Gao, Z.; Ni, G.H.; Grimmond, C.S.B. Attribution and mitigation of heat wave-induced urban heat storage change. Environ. Res. Lett. 2017, 12, 114007. [CrossRef]

23. Founda, D.; Santamouris, M. Synergies between urban heat island and heat waves in Athens (Greece), during and extremely hot summer. Sci. Rep. 2017, 7, 10973. [CrossRef] [PubMed]

24. Gunawardena, K.R.; Wells, M.J.; Kershaw, T. Utilising green and bluespace to mitigate urban heat island intensity. Sci. Total Environ. 2017, 584-585, 1040-1055. [CrossRef] [PubMed]

25. Georgescu, M.; Morefield, P.E.; Bierwagen, B.G.; Weaver, C.P. Twenty-first century megapolitan expansion. Proc. Natl. Am. Sci. USA 2014, 111, 2909-2914. [CrossRef] [PubMed]

26. Kyriakodis, G.-E.; Santamouris, M. Using reflective pavements to mitigate urban heat island in warm climates-Results from a large-scale urban mitigation project. Urban Clim. 2017, 24, 326-339. [CrossRef]

27. Chatzidimitriou, A.; Yannas, S. Microclimate design for open spaces: Ranking urban design effects on pedestrian thermal comfort in summer. Sustain. Cities Soc. 2016, 26, 27-47. [CrossRef]

28. Takebayashi, H. High-Reflectance Technology on Building Façades: Installation Guidelines for Pedestrian Comfort. Sustainability 2016, 8, 785. [CrossRef]

29. Santamouris, M. Urban warming and mitigation: Actual status, impacts and challenges. In Urban Climate Mitigation Techniques; Santamouris, M., Kolokotsa, D., Eds.; Routledge: New York, NU, USA, 2016; pp. 1-25, ISBN 978-0-415-71213-2.

30. Morini, E.; Touchaei, A.-G.; Rossi, F.; Cotana, F.; Akbari, H. Evaluation of albedo enhancement to mitigate impacts of urban heat island in Rome (Italy) using WRF meteorological model. Urban Clim. 2017, 24, 551-566. [CrossRef]

31. Muscio, A. The solar reflectance index as a tool to forecast the heat released to the urban environment: Potentiality and assessment issues. Climate 2018, 6, 12. [CrossRef]

32. Santamouris, M.; Synnefa, A.; Karlessi, T. Using advanced cool materials in the urban built environment to mitigate heat islands and improve thermal comfort conditions. Sol. Energy 2011, 85, 3085-3102. [CrossRef]

33. Bretz, S.E.; Akbari, H.; Rosenfeld, A. Practical issues for using solar-reflective materials to mitigate urban heat islands. Atmos. Environ. 1998, 32, 95-101. [CrossRef] 
34. Aleksandrowicz, O.; Vuckovic, M.; Kiesel, K.; Mahdavi, A. Current trends in urban heat island mitigation research: Observations based on a comprehensive research repository. Urban Clim. 2017, 21, 1-26. [CrossRef]

35. Santamouris, M.; Ding, L.; Fiorito, F.; Synnefa, A. Passive and active cooling for the outdoor environmentAn analysis and assessment of the cooling potential of mitigation technologies using performance data from 220 large-scale projects. Sol. Energy 2017, 154, 14-33. [CrossRef]

36. Pisello, A.L. State of the art on the development of cool coatings for buildings and cities. Sol. Energy 2017, 144, 660-680. [CrossRef]

37. Lee, H.; Mayer, H. Thermal comfort of pedestrians in an urban street canyon is affected by increasing albedo of building wall. Int. J. Biometeorol. 2018. [CrossRef] [PubMed]

38. Lontorfos, V.; Efthymiou, C.; Santamouris, M. On the time varying mitigation performance of reflective geoengineering technologies in cities. Renew. Energy 2018, 115, 926-930. [CrossRef]

39. Yang, J.; Wang, Z.H.; Kaloush, K.E. Environmental impacts of reflective materials: Is high albedo a "silver bullet" for mitigating urban heat island? Renew. Sustain. Energy Rev. 2015, 47, 830-843. [CrossRef]

40. Nunez, M.; Oke, T.R. The energy balance of an urban canyon. J. Appl. Meteorol. 1977, 16, 11-19. [CrossRef]

41. Anandakumar, K. A study on the partition of net radiation into heat fluxes on a dry asphalt surface. Atmos. Environ. 1999, 33, 3911-3918. [CrossRef]

42. Brownlee, J.; Ray, P.; Tewari, M.; Tan, H. Relative role of turbulent and radiative flux on the near-surface temperature in a single-layer urban canopy model over Houston. J. Appl. Meteorol. Climatol. 2017, 56, $2173-2187$. [CrossRef]

43. Qin, Y.; Hiller, J.E. Understanding pavement-surface energy balance and its implications on cool pavement development. Energy Build. 2014, 85, 389-399. [CrossRef]

44. Synnefa, A.; Santamouris, M. Mitigating the urban heat with cool materials for the building's fabric. In Urban Climate Mitigation Techniques; Santamouris, M., Kolokotsa, D., Eds.; Routledge: New York, NY, USA, 2016; pp. 67-91, ISBN 978-0-415-71213-2.

45. Costanzo, V.; Evola, G.; Marletta, L.; Gagliano, A. Proper evaluation of the external convective heat transfer for the thermal analysis of cool roofs. Energy Build. 2014, 77, 467-477. [CrossRef]

46. Akbari, H.; Kolokotsa, D. Three decades of urban heat islands and mitigation technologies research. Energy Build. 2016, 133, 834-842. [CrossRef]

47. Takebayashi, H.; Moriyama, M. Relationships between the properties of an urban street canyon and its radiant environment: Introduction of appropriate urban heat island mitigation technologies. Sol. Energy 2012, 86, 2255-2262. [CrossRef]

48. Ban-Weiss, G.A.; Woods, J.; Levinson, R. Using remote sensing to quantify albedo of roofs in seven California cities, Part 1: Methods. Sol. Energy 2015, 115, 777-790. [CrossRef]

49. Crum, S.M.; Jenerette, G.D. Microclimate Variation among Urban Land Covers: The Importance of Vertical and Horizontal Structure in Air and Land Surface Temperature Relationships. J. Appl. Meteorol. Climatol. 2017, 56, 2531-2543. [CrossRef]

50. Taha, H. Urban climates and heat islands: Albedo, evapotranspiration, and anthropogenic heat. Energy Build. 1997, 25, 99-103. [CrossRef]

51. Levinson, R.M. Near-Ground Cooling Efficacies of Trees and High-Albedo Surfaces. Ph.D. Thesis, University of California, Berkeley, CA, USA, 1997.

52. Lee, I.; Voogt, J.A.; Gillespie, T.J. Analysis and comparison of shading strategies to increase human thermal comfort in urban areas. Atmosphere 2018, 9, 91. [CrossRef]

53. Taleghani, M. The impact of increasing urban surface albedo on outdoor summer thermal comfort within a university campus. Urban Clim. 2018, 24, 175-184. [CrossRef]

54. Rosso, F.; Golasi, I.; Castaldo, V.L.; Piselli, C.; Pisello, A.L.; Salata, F.; Ferrero, M.; Cotana, F.; de Lieto Vollaro, A. On the impact of innovative materials on outdoor thermal comfort of pedestrians in historical urban canyons. Renew. Energy 2018, 118, 825-839. [CrossRef]

55. Taleghani, M.; Berardi, U. The effect of pavement characteristics on pedestrians' thermal comfort in Toronto. Urban Clim. 2017, 24, 449-459. [CrossRef]

56. Hardin, A.W.; Vanos, J.K. The influence of surface type on the absorbed radiation by a human under hot, dry conditions. Int. J. Biometeorol. 2018, 62, 43-56. [CrossRef] [PubMed] 
57. Yoshida, S.; Yumino, S.; Uchida, T.; Mochida, A. Numerical Analysis of the Effects of Windows with Heat Ray Retro-reflective Film on the Outdoor Thermal Environment within a Two-dimensional Square Cavity-type Street Canyon. Procedia Eng. 2016, 169, 384-391. [CrossRef]

58. Salata, F.; Golasi, I.; Vollaro, E.D.L.; Bisegna, F.; Nardecchia, F.; Coppi, M.; Gugliermetti, F.; Vollaro, A.D.L. Evaluation of different urban microclimate mitigation strategies through a PMV analysis. Sustainability 2015, 7, 9012-9030. [CrossRef]

59. Erell, E.; Pearlmutter, D.; Boneh, D.; Kutiel, P.B. Effect of high-albedo materials on pedestrian heat stress in urban street canyons. Urban Clim. 2014, 10, 367-386. [CrossRef]

60. Laureti, F.; Martinelli, L.; Battisti, A. Assessment and mitigation strategies to counteract overheating in urban historical areas in Rome. Climate 2018, 6, 18. [CrossRef]

61. Coakley, J.A. Reflectance and albedo, surface. In Encyclopedia of Atmospheric Sciences; Holton, J.R., Ed.; Academic Press: Oxford, UK, 2003; pp. 1914-1923, ISBN 9780122270901.

62. Levinson, R.M.; Akbari, H.; Berdahl, P. Measuring solar reflectance-Part 1: Defining a metric that accurately predicts solar heat gain. Sol. Energy 2010, 84, 1717-1744. [CrossRef]

63. Schaepman-Strub, G.; Schaepman, M.E.; Painter, T.H.; Dangel, S.; Martonchik, J.V. Reflectance quantities in optical remote sensing-definitions and case studies. Remote Sens. Environ. 2006, 103, 27-42. [CrossRef]

64. Sailor, D.J.; Resh, K.; Segura, D. Field measurement of albedo for limited extent test surfaces. Sol. Energy 2006, 80, 589-599. [CrossRef]

65. Qin, Y.; He, H. A new simplified method for measuring the albedo of limited extent targets. Sol. Energy 2017, 157, 1047-1055. [CrossRef]

66. Levinson, R.; Akbari, H.; Berdahl, P. Measuring solar reflectance-Part 2: Review of practical methods. Sol. Energy 2010, 84, 1745-1759. [CrossRef]

67. ASTM International. ASTM E903-12, Standard Test Method for Solar Absorptance, Reflectance and Transmittance of Materials Using Integrating Spheres; ASTM International: West Conshohocken, PA, USA, 2012.

68. ASTM International. ASTM C1549-16, Standard Test Method for Determination of Solar Reflectance Near Ambient Temperature Using a Portable Solar Reflectometer; ASTM International: West Conshohocken, PA, USA, 2016.

69. ASTM International. ASTM E1918-16, Standard Test Method for Measuring Solar Reflectance of Horizontal and Low-Sloped Surfaces in the Field; ASTM International: West Conshohocken, PA, USA, 2016.

70. Akbari, H.; Levinson, R.; Berdahl, P. Cool materials rating instrumentation and testing. In Advances in the Development of Cool Materials for the Built Environment; Kolokotsa, D., Santamouris, M., Akbari, H., Eds.; Bentham Science Publishers: Oak Park, IL, USA, 2013; pp. 47-76, ISBN 978-1-60805-597-5.

71. Mei, G.; Wu, B.; Ma, S.; Qin, Y. A simplified method for the solar reflectance of a finite surface in field. Measurement 2017, 110, 211-216. [CrossRef]

72. Qin, Y.; Liang, J.; Tan, K.; Li, F. A side-by-side comparison of the cooling effect of building blocks with retro-reflective and diffuse-reflective walls. Sol. Energy 2016, 133, 172-179. [CrossRef]

73. Rossi, F.; Castellani, B.; Presciutti, A.; Morini, E.; Filipponi, M.; Nicolini, A.; Santamouris, M. Retroreflective façades for urban heat island mitigation: Experimental investigation and energy evaluations. Appl. Energy 2015, 145, 8-20. [CrossRef]

74. Pisello, A.L.; Goretti, M.; Cotana, F. A method for assessing buildings' energy efficiency by dynamic simulation and experimental activity. Appl. Energy 2012, 97, 419-429. [CrossRef]

75. Voogt, J.A.; Oke, T.R. Radiometric temperatures of urban canyon walls obtained from vehicle traverses. Theor. Appl. Climatol. 1998, 60, 199-217. [CrossRef]

76. Johnson, G.T.; Watson, I.D. The Determination of View-Factors in Urban Canyons. J. Clim. Appl. Meteorol. 1984, 23, 329-335. [CrossRef]

77. Krayenhoff, E.S.; Voogt, J.A. Daytime thermal anisotropy of urban neighbourhoods: Morphological causation. Remote Sens. 2016, 8, 108. [CrossRef]

78. Adderley, C.A.; Christen, A.; Voogt, J.A. The effect of radiometer placement and view on inferred directional and hemispheric radiometric temperatures of an urban canopy. Atmos. Meas. Tech. Discuss. 2015, 8, 2699-2714. [CrossRef]

79. Hénon, A.; Mestayer, P.G.; Lagouarde, J.P.; Voogt, J.A. An urban neighborhood temperature and energy study from the CAPITOUL experiment with the Solene model. Part 2: Influence of building surface heterogeneities. Theor. Appl. Climatol. 2012, 110, 197-208. [CrossRef] 
80. Christen, A.; Meier, F.; Scherer, D. High-frequency fluctuations of surface temperatures in an urban environment. Theor. Appl. Climatol. 2012, 108, 301-324. [CrossRef]

81. Lagouarde, J.P.; Hénon, A.; Kurz, B.; Moreau, P.; Irvine, M.; Voogt, J.; Mestayer, P. Modelling daytime thermal infrared directional anisotropy over Toulouse city centre. Remote Sens. Environ. 2010, 114, 87-105. [CrossRef]

82. Voogt, J.A. Assessment of an urban sensor view model for thermal anisotropy. Remote Sens. Environ. 2008, 112, 482-495. [CrossRef]

83. Allen, M.A.; Voogt, J.A.; Christen, A. Time-Continuous hemispherical urban surface temperatures. Remote Sens. 2018, 10, 3. [CrossRef]

84. Richards, J.A. Remote Sensing Digital Image Analysis, an Introduction, 5th ed.; Springer: Heidelberg, Germany, 2013; ISBN 978-3-642-30062-2.

85. Kurz, T.H.; Buckley, S.J.; Howell, J.A. Close-range hyperspectral imaging for geological field studies: Workflow and methods. Int. J. Remote Sens. 2013, 34, 1798-1822. [CrossRef]

86. Iqbal, F.; Lucieer, A.; Barry, K. Simplified radiometric calibration for UAS-mounted multispectral sensor. Eur. J. Remote Sens. 2018, 51, 301-313. [CrossRef]

87. Del Pozo, S.; Rodríguez-Gonzálvez, P.; Hernández-López, D.; Felipe-García, B. Vicarious radiometric calibration of a multispectral camera on board an unmanned aerial system. Remote Sens. 2014, 6, 1918-1937. [CrossRef]

88. Smith, G.M.; Milton, E.J. The use of the empirical line method to calibrate remotely sensed data to reflectance. Int. J. Remote. Sens. 1999, 20, 2653-2662. [CrossRef]

89. Brest, C.L.; Goward, S.N. Deriving surface albedo measurements from narrow band satellite data. Int. J. Remote Sens. 2007, 8, 351-367. [CrossRef]

90. Synnefa, A.; Santamouris, M.; Apostolakis, K. On the development, optical properties and thermal performance of cool colored coatings for the urban environment. Sol. Energy 2007, 81, 488-497. [CrossRef]

91. Tetracam Inc. Agricultural Digital Camera (ADC) Specifications. 2016. Available online: www.tetracam.com (accessed on 25 November 2015).

92. Del Pozo, S.; Sánchez-Aparicio, L.J.; Rodríguez-Gonzálvez, P.; Herrero-Pascual, J.; Muñoz-Nieto, A.; González-Aguilera, D.; Hernández-López, D. Multispectral imaging: Fundamentals, principles and methods of damage assessment in constructions. In Non-Destructive Techniques for the Evaluation of Structures and Infrastructure; Riveiro, B., Solla, M., Eds.; CRC Press: London, UK, 2016; pp. 139-166, ISBN 9781315685151.

93. Corripio, J.G. Snow surface albedo estimation using terrestrial photography. Int. J. Remote Sens. 2004, 25, 5705-5729. [CrossRef]

94. Pompilio, L.; Marinangeli, L.; Amitrano, L.; Pacci, G.; D’andrea, S.; Iacullo, S.; Monaco, E. Application of the empirical line method (ELM) to calibrate the airborne Daedalus-CZCS scanner. Eur. J. Remote Sens. 2018, 51, 33-46. [CrossRef]

95. Berra, E.F.; Gaulton, R.; Barr, S. Commercial off-the-shelf digital cameras on unmanned aerial vehicles for multi-temporal monitoring of vegetation reflectance and NDVI. IEEE Trans. Geosci. Remote Sens. 2017, 55, 4878-4886. [CrossRef]

96. Mathews, A.J. A practical UAV remote sensing methodology to generate multispectral orthophotos for vineyards: Estimation of spectral reflectance using compact digital cameras. Int. J. Appl. Geospace Res. 2015, 6, 65-87. [CrossRef]

97. Stow, D.; Hope, A.; Nguyen, A.T.; Phinn, S.; Benkelman, C.A. Monitoring detailed land surface changes using an airborne multispectral digital camera system. IEEE Trans. Geosci. Remote Sens. 1996, 34, 1191-1203. [CrossRef]

98. Wang, C.; Myint, S.W. A Simplified empirical line method of radiometric calibration for small unmanned aircraft systems-based remote sensing. IEEE J. Sel. Top. Appl. Earth Obs. Remote Sens. 2015, 8, 1876-1885. [CrossRef]

99. Herrero-Huerta, M.; Hernández-López, D.; Rodriguez-Gonzalvez, P.; González-Aguilera, D.; González-Piqueras, J. Vicarious radiometric calibration of a multispectral sensor from an aerial trike applied to precision agriculture. Comput. Electron. Agric. 2014, 108, 28-38. [CrossRef]

100. Honkavaara, E.; Arbiol, R.; Markelin, L.; Martinez, L.; Cramer, M.; Bovet, S.; Chandelier, L.; Ilves, R.; Klonus, S.; Marshal, P.; et al. Digital airborne photogrammetry-A new tool for quantitative remote sensing?-A state-of-the-art review on radiometric aspects of digital photogrammetric images. Remote Sens. 2009, 1, 577-605. [CrossRef] 
101. Zaman, B.; Austin, J.; Clemens, S.; McKee, M. Retrieval of spectral reflectance of high-resolution multispectral imagery acquired with an autonomous unmanned aerial vehicle: Aggieair ${ }^{\mathrm{TM}}$. Photogramm. Eng. Remote Sens. 2014, 80, 1139-1150. [CrossRef]

102. Laliberte, A.S.; Goforth, M.A.; Steele, C.M.; Rango, A. Multispectral remote sensing from unmanned aircraft: Image processing workflows and applications for rangeland environments. Remote Sens. 2011, 3, 2529-2551. [CrossRef]

103. Mei, A.; Bassani, C.; Fortinovo, G.; Salvatori, R.; Allegrini, A. The use of suitable pseudo-invariant targets for MIVIS data calibration by the empirical line method. ISPRS J. Photogramm. Remote Sens. 2016, 114, 102-114. [CrossRef]

104. Gaitani, N.; Burud, I.; Thiis, T.; Santamouris, M. High-resolution spectral mapping of urban thermal properties with Unmanned Aerial Vehicles. Build. Environ. 2017, 121, 215-224. [CrossRef]

105. Qin, Y.; Liang, J.; Tan, K.; Li, F. The amplitude and maximum of daily pavement surface temperature increase linearly with solar absorption. Road Mater. Pavement Des. 2017, 18, 440-452. [CrossRef]

106. Kolokotsa, D.D.; Giannariakis, G.; Gobakis, K.; Giannarakis, G.; Synnefa, A.; Santamouris, M. Cool roofs and cool pavements application in Acharnes, Greece. Sustain. Cities Soc. 2018, 37, 466-474. [CrossRef]

107. Qin, Y. A review on the development of cool pavements to mitigate urban heat island effect. Renew. Sustain. Energy Rev. 2015, 52, 445-459. [CrossRef]

108. Pisello, A.L.; Castaldo, V.L.; Piselli, C.; Fabiani, C.; Cotana, F. Thermal performance of coupled cool roof and cool façade: Experimental monitoring and analytical optimization procedure. Energy Build. 2017, 157, 35-52. [CrossRef]

109. Zinzi, M. Exploring the potentialities of cool facades to improve the thermal response of Mediterranean residential buildings. Sol. Energy 2016, 135, 386-397. [CrossRef]

110. Zinzi, M. Characterisation and assessment of near infrared reflective paintings for building facade applications. Energy Build. 2016, 114, 206-213. [CrossRef]

111. Rossi, F.; Pisello, A.L.; Nicolini, A.; Filipponi, M.; Palombo, M. Analysis of retro-reflective surfaces for urban heat island mitigation: A new analytical model. Appl. Energy 2014, 114, 621-631. [CrossRef]

112. Hernández-Pérez, I.; Álvarez, G.; Xamán, J.; Zavala-Guillén, I.; Arce, J.; Simá, E. Thermal performance of reflective materials applied to exterior building components-A review. Energy Build. 2014, 80, 81-105. [CrossRef]

113. Georgakis, C.; Zoras, S.; Santamouris, M. Studying the effect of "cool" coatings in street urban canyons and its potential as a heat island mitigation technique. Sustain. Cities Soc. 2014, 13, 20-31. [CrossRef]

114. Fiorito, F.; Santamouris, M. High performance technologies and the future of architectural design. TECHNE J. Technol. Archit. Environ. 2017, 80, 72-76. [CrossRef]

115. Sung, D. A New Look at Building Facades as Infrastructure. Engineering 2016, 2, 63-68. [CrossRef]

116. Libbra, A.; Muscio, A.; Siligardi, C. Energy performance of opaque building elements in summer: Analysis of a simplified calculation method in force in Italy. Energy Build. 2013, 64, 384-394. [CrossRef]

117. Halawa, E.; Ghaffarianhoseini, A.; Ghaffarianhoseini, A.; Trombley, J.; Hassan, N.; Baig, M.; Yusoff, S.Y.; Ismail, M.A. A review on energy conscious designs of building façades in hot and humid climates: Lessons for (and from) Kuala Lumpur and Darwin. Renew. Sustain. Energy Rev. 2018, 82, 2147-2161. [CrossRef]

118. Castaldo, V.L.; Pisello, A.L.; Piselli, C.; Fabiani, C.; Cotana, F.; Santamouris, M. How outdoor microclimate mitigation affects building thermal-energy performance: A new design-stage method for energy saving in residential near-zero energy settlements in Italy. Renew. Energy 2018, 127, 920-935. [CrossRef]

119. Lamarca, C.; Quense, J.; Henríquez, C. Thermal comfort and urban canyons morphology in coastal temperature climate, Conception, Chile. Urban Clim. 2018, 23, 159-172. [CrossRef]

120. Song, D.; Han, S. The Analysis of Reactive Factors between Architectural Envelop Condition and Urban Microclimate. Procedia Eng. 2016, 169, 125-132. [CrossRef]

121. Garuma, G.M. Review of urban surface parameterizations for numerical climate models. Urban Clim. 2017, 24, 830-851. [CrossRef]

122. Bozonnet, E.; Musy, M.; Calmet, I.; Rodriguez, F. Modeling methods to assess urban fluxes and heat island mitigation measures from street to city scale. Int. J. Low-Carbon Technol. 2015, 10, 62-77. [CrossRef]

123. Best, M.J.; Grimmond, C.S.B. Key conclusions of the first international urban land surface model comparison project. BAMS 2015, 96, 805-819. [CrossRef]

124. Velasco, E. Go to field, look around, measure and then run models. Urban Clim. 2018, 24, 231-236. [CrossRef] 
125. Page, J.K. The fundamental problems of building climatology considered from the point of view of decision-making by the architect or urban designer. In Building Climatology, Proceedings of the Symposium on Urban Climates and Building Climatology; WMO Technical Note 10; WHO: Switzerland, Geneva, 1968; Volume 2, pp. 9-21.

126. Barlow, J.; Best, M.; Bohnenstengel, S.I.; Clark, P.; Grimmond, S.; Lean, H.; Christen, A.; Emeis, S.; Haeffelin, M.; Harman, I.N. Developing a research strategy to better understand, observe and simulate urban atmospheric processes at kilometre to sub-kilometre scales. BAMS 2017, 98, ES261-ES264. [CrossRef]

127. Australian Government Civil Aviation Safety Authority. CASR Part 101-Unmanned Aircraft and Rockets. Available online: https: / www.casa.gov.au/standard-page/ casr-part-101-unmanned-aircraft-and-rocketoperations (accessed on 2 April 2018).

128. Willmott, C.J. On the validation of models. Phys. Geogr. 1981, 2, 184-194. [CrossRef]

129. Willmott, C.J. Some comments on the evaluation of model performance. BAMS 1982, 63, 1309-1313. [CrossRef]

130. Labsphere Inc. $8^{\circ}$ /Hemispherical Reflectance Multi-Step Target Certificate; Serial number MS050-0916-6020; Labsphere Inc.: North Sutton, NH, USA, 2016.

131. Geoscience Australia, Commonwealth of Australia. Available online: http://www.ga.gov.au/geodesy/ astro/smpos.jsp (accessed on 3 June 2017).

132. Baugh, W.M.; Groeneveld, D.P. Empirical proof of the empirical line. Int. J. Remote Sens. 2008, $29,665-672$. [CrossRef]

133. PixelWrench II, Proprietary Image Editing Software, version 1.2.1.8; Tetracam Inc.: Chatsworth, CA, USA, 2015.

134. Huang, Y.; Thomson, S.J.; Lan, Y.; Maas, S.J. Multispectral imaging systems for airborne remote sensing to support agricultural production management. Int. J. Agric. Biol. Eng. 2010, 3, 50-62. [CrossRef]

135. Honkavaara, E.; Hakala, T.; Peltoniemi, J.; Suomalainen, J.; Ahokas, E.; Markelin, L. Analysis of properties of reflectance reference targets for permanent radiometric test sites of high resolution airborne imaging systems. Remote Sens. 2010, 2, 1892-1917. [CrossRef]

136. Moran, M.S.; Bryant, R.; Thome, K.; Ni, W.; Nouvellon, Y.; Gonzalez-Dugo, M.P.; Qi, J.; Clarke, T.R. A refined empirical line approach for reflectance factor retrieval from Landsat-5 TM and Landsat-7 ETM+. Remote Sens. Environ. 2001, 78, 71-82. [CrossRef]

137. Willmott, C.J.; Ackleson, S.G.; Davis, R.E.; Feddema, J.J.; Klink, K.M.; Legates, D.R.; O'donnell, J.; Rowe, C.M. Statistics for the evaluation and comparison of models. J. Geophys. Res. 1985, 90, 8995-9005. [CrossRef]

138. Piñeiro, G.; Perelman, S.; Guerschman, J.P.; Paruelo, J.M. How to evaluate models: Observed vs. predicted or predicted vs. observed? Ecol. Model. 2008, 216, 316-322. [CrossRef]

139. Willmott, C.J.; Matsuura, K. Advantages of the mean absolute error (MAE) over the root mean square error (RMSE) in assessing average model performance. Clim. Res. 2005, 30, 79-82. [CrossRef]

140. Hyslop, N.P.; White, W.H. Estimating Precision Using Duplicate Measurements. J. Air Waste Manag. Assoc. 2009, 59, 1032-1039. [CrossRef] [PubMed]

141. Smith, E.P.; Rose, K.A. Model goodness-of-fit analysis using regression and related techniques. Ecol. Model. 1995, 77, 49-64. [CrossRef]

142. Chen, P.Y.; Popovich, P.M. Correlation: Parametric and Non-Parametric Measures; Sage University Paper Series on Quantitative Applications in the Social Sciences, Series No. 07-139; Sage: Irvine, CA, USA, 2002; ISBN 0761922288.

143. Lewis-Beck, M.S. Data Analysis, an Introduction; Sage University Paper Series on Quantitative Applications in the Social Sciences, Series No. 07-103; Sage: Irvine, CA, USA, 1995; ISBN 0803957726.

144. Gibbons, J.D. Nonparametric Statistics: An Introduction; Sage University Paper Series on Quantitative Applications in the Social Sciences, Series No. 07-090; Sage: Irvine, CA, USA, 1993; ISBN 0803946643.

145. Hueni, A.; Damm, A.; Kneubuehler, M.; Schlapfer, D.; Schaepman, M.E. Field and airborne spectroscopy cross validation-Some considerations. IEEE J. Sel. Top. Appl. Earth Obs. Remote Sens. 2017, 10, 1117-1135. [CrossRef]

146. Zinzi, M.; Carnielo, E.; Rossi, G. Directional and angular response of construction materials solar properties: Characterisation and assessment. Sol. Energy 2015, 115, 52-67. [CrossRef]

147. Dangel, S.; Verstraete, M.M.; Schopfer, J.; Kneubuhler, M.; Schaepman, M.; Itten, K.I. Toward a direct comparison of field and laboratory goniometer measurements. IEEE Trans. Geosci. Remote Sens. 2005, 43, 2666-2675. [CrossRef] 
148. Del Pozo, S.; Herrero-Pascual, J.; Felipe-García, B.; Hernández-López, D.; Rodríguez-Gonzálvez, P.; González-Aguilera, D. Multispectral radiometric analysis of façades to detect pathologies from active and passive remote sensing. Remote Sens. 2016, 8, 80. [CrossRef]

149. Honkavaara, E. Calibrating Digital Photogrammetric Airborne Imaging Systems Using a Test Field. Ph.D. Thesis, University of Technology Espoo, Espoo, Finland, 2008. 